\title{
Research Progress on Corrosion Resistance of Magnesium Alloys with Bio-inspired Water-repellent Properties: A Review
}

\author{
Jinkai Xu*, Qianqian Cai, Zhongxu Lian*, Zhanjiang Yu, Wanfei Ren, Huadong Yu \\ Key Laboratory for Cross-Scale Micro and Nano Manufacturing, Changchun University of \\ Science and Technology, Changchun 130022, China
}

\begin{abstract}
Thanks to its excellent mechanical properties, magnesium alloys have many potential applications in the aerospace and other fields. However, failure to adequately solve corrosion problems of magnesium alloy becomes one of the factors restricting its wide use in many industrial fields. Inspired by nature, researchers designed and fabricated bio-inspired water-repellent (superhydrophobic and slippery liquid-infused porous surface) surfaces with special wetting properties by exploring the surface microstructures of plants and animals such as lotus leaf and nepenthes pitcher, exhibiting excellent corrosion-resistant performance. This article summarizes the research progress on corrosion resistance of magnesium alloys with bio-inspired water-repellent properties in recent years. It mainly introduces the corrosion reasons, types of corrosion of magnesium alloys, and the preparation of magnesium alloys with bio-inspired water-repellent properties to improve corrosion resistance. In particular, it is widely used and effective to construct water-repellent and anti-corrosion coating on the surface of magnesium alloy by surface treatment. It is hoped that the research in this review can broaden the application range of magnesium alloys and provide a powerful reference for the future research on corrosion resistance of magnesium alloys.
\end{abstract}

Keywords: magnesium alloy, bio-inspired water-repellent, corrosion resistance, superhydrophobic, slippery liquid-infused porous surface, research progress

Copyright $($ C The author(s) 2021.

\section{Introduction}

Magnesium alloy has the advantages of light weight, high specific strength and specific rigidity, good shock absorption performance, excellent electrical and thermal conductivity, and is easy to cut and renewable ${ }^{[1-6]}$. It is recognized as the most promising lightweight and green engineering material, and has many potential applications and increasingly positive development prospects in the fields of aerospace, transportation, electronic devices, biomedicine, and our daily life $^{[7-11]}$. Magnesium and its alloys are expected to become alternative materials for other traditional metals by virtue of abundant resources and many excellent properties $^{[12-15]}$.

The positive prospect of magnesium alloy as a structural material, however, is in distinct contrast to the situation it has been facing nowadays ${ }^{[16]}$. One of the reasons is the corrosion problem of magnesium ${ }^{[17,18]}$. As a matter of fact, the chemical properties of magnesium are very active, and its standard electrode potential is
$-2.37 \mathrm{~V}$, which is lower than that of $\mathrm{Fe}, \mathrm{Zn}, \mathrm{Al}$ and other metal elements ${ }^{[19,20]}$. It is very easy to form galvanic corrosion with impurity elements or the second phase ${ }^{[21]}$. Moreover, magnesium alloy products are also easily oxidized during processing and use $\mathrm{e}^{[22-24]}$, and thus the loose and porous surface oxide film is difficult to form stable and effective protection for the alloy ${ }^{[25,26]}$. It is obvious that poor corrosion resistance has become a bottleneck restricting the potential of magnesium alloys ${ }^{[27]}$. Therefore, improving the corrosion resistance of magnesium alloys is not only extremely important in practical applications but can offer significant economic returns $^{[28,29]}$.

At present, the main methods to improve the corrosion resistance and extend the service life of magnesium alloys include micro-alloying ${ }^{[30-32]}$, microstructure contro ${ }^{[33,34]}$, surface treatment ${ }^{[35,36]}$ and preparation of functional coatings ${ }^{[37]}$. The widely used and effective method is to construct a coating with anti-corrosion performance on the surface of magnesium alloy through surface treatment ${ }^{[38,39]}$. Bio-inspired water-repellent

*Corresponding author: Jinkai Xu, Zhongxu Lian

E-mail: xujinkai2000@163.com, lianzhongxv@126.com 
surfaces with its unique interface characteristics and advantages have become a new idea to solve the corrosion problems of metal materials ${ }^{[40,41]}$. The bio-inspired water-repellent surfaces introduced in this article are divided into superhydrophobic surfaces and Slippery Liquid-Infused Porous Surfaces (SLIPSs) ${ }^{[42,43]}$. The fabrication of magnesium-based bio-inspired water-repellent surface helps to construct a function on the substrate of magnesium alloy, improving the corrosion resistance of magnesium alloy in an effective manner ${ }^{[44-46]}$. The fabricated bio-inspired water-repellent surfaces can effectively cut off the direct contact of corrosion medium such as humid air and erosion solution to the magnesium alloy substrate and reduce the corrosion $^{[47-49]}$.

This article summarizes the research progress of corrosion resistance of magnesium alloys in five parts covering factors which affect corrosion and different types of corrosion, basic principle of wettability and practical applications of the bio-inspired water-repellent surface in corrosion resistance of magnesium alloys and highlights the development of corrosion resistance of bio-inspired water-repellent magnesium alloys as well as scientific problems.

\section{Corrosion of magnesium alloy}

\subsection{Influencing factors of magnesium alloy corrosion}

Magnesium alloys are prone to electrochemical reactions under the corrosion environment of simulated seawater. The reaction process is as follows ${ }^{[50,51]}$ :

$$
\mathrm{Mg}(\mathrm{s})+2 \mathrm{H}_{2} \mathrm{O}(\mathrm{aq}) \rightarrow \mathrm{Mg}(\mathrm{OH})_{2}(\mathrm{~s})+\mathrm{H}_{2} \uparrow,
$$

where the electrolyte is a $\mathrm{NaCl}$ aqueous solution, $\mathrm{Cl}^{-}$is a corrosive medium, and the $\mathrm{Mg}^{2+}$ produced by the anode reaction will react with $\mathrm{Cl}^{-}$. The reaction equation is:

$$
\mathrm{Mg}^{2+}+2 \mathrm{Cl}^{-} \rightarrow \mathrm{MgCl}_{2} .
$$

In practical applications, there are many factors that affect the corrosion of magnesium alloys: alloy elements $^{[52-54]}$, secondary phase size and distribution ${ }^{[55,56]}$, grain size $\mathrm{e}^{[57-59]}$, crystal orientation and texture strength $^{[60,61]}$, crystal defects ${ }^{[62,63]}$, and environmental factors ${ }^{[64-66]}$ (Fig. 1). The corrosion of magnesium alloys is mostly galvanic corrosion, and the $\alpha-\mathrm{Mg}$ substrate is mainly corroded. Therefore, the corrosion resistance of the substrate is the key to determining the corrosion behavior of the entire alloy. Researchers analyzed the factors affecting the corrosion of magnesium alloy, and improved the corrosion resistance of magnesium alloy by a number of measures including adding alloy elements ${ }^{[67-71]}$, reducing the size of the second phase and making the distribution uniform ${ }^{[72-76]}$, refining the grains $^{[77-81]}$, changing the crystal orientation and texture strength $^{[82-86]}$ as well as reducing crystal defects ${ }^{[87-89]}$ (Fig. 2). Table 1 summarizes some of factors which affect the corrosion resistance of magnesium alloy.

Adding alloy elements may change the chemical components of magnesium alloy directly or indirectly and drive change in its form of organization, and the second phase size and distribution, consequently improving the corrosion resistance behavior of magnesium alloy ${ }^{[00,91]}$. On the other hand, grain size of magnesium alloy can be reduced by alloying ${ }^{[22]}$ and plastic deformation ${ }^{[93]}$, so that mechanical properties of alloys can be improved effectively. Thus, fine grain strengthening is one of the key ways to improve the mechanical properties of magnesium alloy, and changing the grain size will create an important impact on corrosion resistance of magnesium alloy ${ }^{[94,95]}$. The presence of alloying elements will lead to the appearance of a second phase in the magnesium alloy. The second phase is usually a compound of $\mathrm{Mg}$ and $\mathrm{A}{ }^{[96,97]}, \mathrm{Zn}^{[98]}$, rare earth and other metal elements ${ }^{[99,100]}$, and its electrochemical stability is higher than that of the matrix phase. Therefore, the corrosion behavior of magnesium alloys is mainly

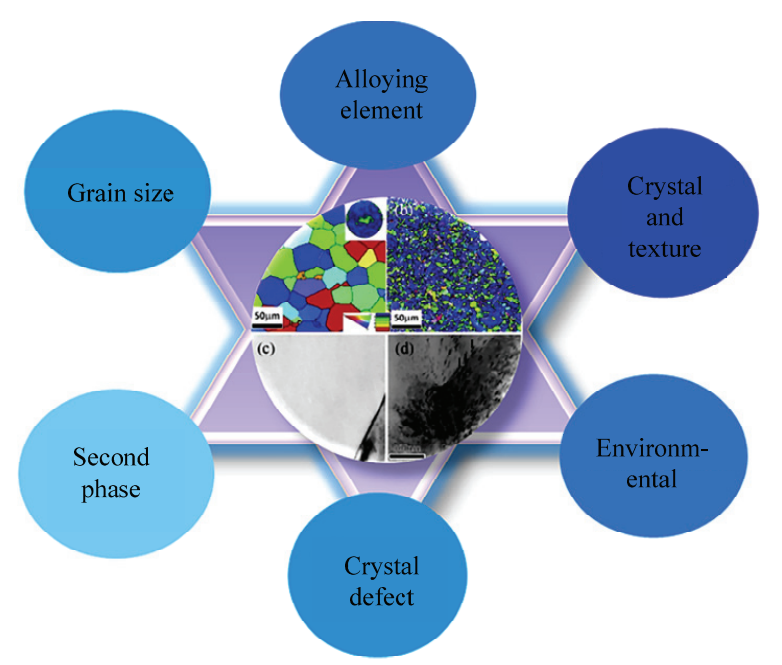

Fig. 1 Main factors influencing corrosion of magnesium alloy ${ }^{[2]}$. 

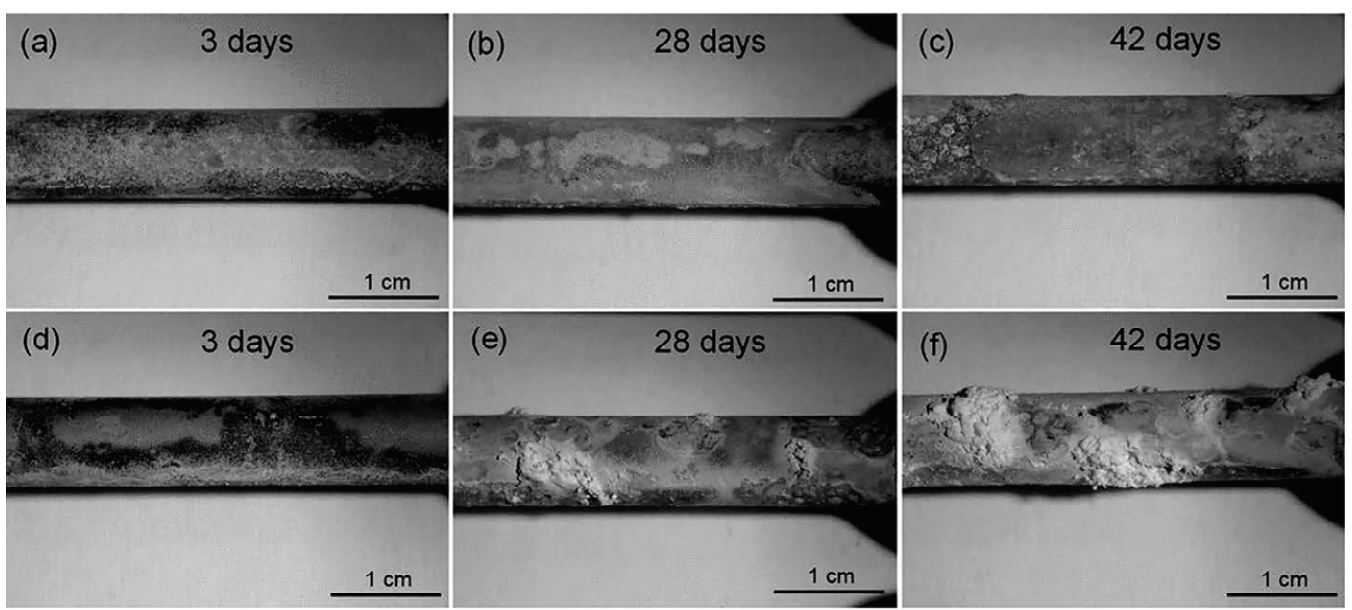

Fig. 2 Morphology of the surface of the salt spray test sample: $(\mathrm{a}-\mathrm{c}) \mathrm{Mg} 0.5 \mathrm{Zn} 0.2 \mathrm{Ca},(\mathrm{d}-\mathrm{f}) \mathrm{Mg} 0.5 \mathrm{Zn} 0.2 \mathrm{Ge}^{[73]}$.

Table 1 Some of factors influencing corrosion resistance of magnesium alloy

\begin{tabular}{|c|c|c|c|c|c|}
\hline Influencing factors & Technology & Material & Functions & Corrosion types & Refs. \\
\hline \multirow[t]{3}{*}{ Alloying element } & Hot-rolling & $\mathrm{Mg}-\mathrm{xSn}-1 \mathrm{Zn}-0.5 \mathrm{Ca}$ & $\begin{array}{l}\text { Good corrosion resistance and mechanical prop- } \\
\text { erties }\end{array}$ & Galvanic corrosion & [67] \\
\hline & Direct-chill casting & $\mathrm{Mg}-0.5 \mathrm{Zn}$ alloy & $\begin{array}{l}\mathrm{Mg}-\mathrm{Zn}-\mathrm{Ca} \text { possessed the highest corrosion } \\
\text { resistance }\end{array}$ & Pitting corrosion & {$[68]$} \\
\hline & $\begin{array}{l}\text { High pressure casting } \\
\text { technology }\end{array}$ & $\mathrm{Mg}-\mathrm{Ga}$ alloy & Good corrosion resistance. & Galvanic corrosion & {$[69]$} \\
\hline \multirow[t]{3}{*}{$\begin{array}{l}\text { Second phase size and } \\
\text { distribution }\end{array}$} & Screw rolling & Mg alloy & $\begin{array}{l}\text { The corrosion rate of the magnesium alloy screw } \\
\text { rolled at } 300{ }^{\circ} \mathrm{C} \text { is the lowest }\end{array}$ & Galvanic corrosion & {$[72]$} \\
\hline & Casting and hot-rolling & AM60 alloy & $\begin{array}{l}\text { AM60+1In alloy has the strongest corrosion } \\
\text { resistance }\end{array}$ & Total corrosion & {$[73]$} \\
\hline & Casting and extrusion & $\mathrm{Mg}-\mathrm{Sm}-\mathrm{Zn}-\mathrm{Zr}$ alloy & The corrosion resistance is increased by 3 times. & Galvanic corrosion & {$[75]$} \\
\hline \multirow[t]{3}{*}{ Grain size } & Hot-rolling & $\mathrm{Mg}-1 \mathrm{Ca}$ alloy & $\begin{array}{c}\text { Refinement of the structure significantly reduces } \\
\text { the corrosion rate }\end{array}$ & Local corrosion & {$[78]$} \\
\hline & Rolling and annealing & AZ61 alloy & $\begin{array}{c}\text { Reduced grain size and improved corrosion } \\
\text { resistance }\end{array}$ & Galvanic corrosion & {$[80]$} \\
\hline & Hot-rolling & $\mathrm{Mg}-4 \mathrm{Li}-1 \mathrm{Ca}$ alloy & Improved alloy strength and corrosion resistance & Total corrosion & {$[81]$} \\
\hline \multirow[t]{3}{*}{$\begin{array}{l}\text { Crystal orientation and } \\
\text { texture strength }\end{array}$} & Rolling & Mg-5Li-1Al alloy & The corrosion resistance of the alloy is improved. & $\begin{array}{l}\text { Hydrogen induced } \\
\text { cracking }\end{array}$ & {$[82]$} \\
\hline & Cut & AZ31 Mg alloy & Improve the corrosion resistance. & $\begin{array}{l}\text { Hydrogen induced } \\
\text { cracking }\end{array}$ & {$[85]$} \\
\hline & $\begin{array}{l}\text { Directional solidifica- } \\
\text { tion }\end{array}$ & $\mathrm{Mg}-4 \mathrm{wt} \% \mathrm{Zn}$ alloy & Improved alloy corrosion resistance. & Pitting corrosion & {$[86]$} \\
\hline \multirow[t]{3}{*}{ Crystal defect } & Cast and extrusion & $\begin{array}{l}\text { AZ91D magnesium } \\
\text { alloy }\end{array}$ & Improved alloy corrosion resistance. & Galvanic corrosion & {$[87]$} \\
\hline & $\begin{array}{l}\text { Compressive defor- } \\
\text { mation }\end{array}$ & $\mathrm{Mg}-\mathrm{Y}$ alloy & $\begin{array}{l}\text { Improved the electrochemical corrosion perfor- } \\
\text { mance. }\end{array}$ & Pitting corrosion & {$[88]$} \\
\hline & Pre-stretch & AZ31 alloy & Improved corrosion resistance & $\begin{array}{l}\text { Hydrogen induced } \\
\text { cracking }\end{array}$ & [89] \\
\hline
\end{tabular}

micro-galvanic corrosion because of the potential difference between the second phase and the substrate $^{[101,102]}$. Although the second phase is generally not corroded, the type, content, morphology and distribution of the second phase can affect the corrosion of the magnesium matrix, so the second phase plays a vital role in the corrosion of magnesium alloys ${ }^{[103,104]}$. However, there are also a few opinions that the increase of grain boundary area will reduce the corrosion resistance of magnesium alloy, and a small number of crystal defects inside the magnesium alloy can provide strong driving force for corrosion reaction, and hence make the surface 
form a thin and dense $\mathrm{Mg}(\mathrm{OH})_{2}$ corrosion protection film, thus delaying the corrosion process and improving the corrosion resistance ${ }^{[105]}$.

\subsection{Corrosion types of magnesium alloy}

The corrosion process of magnesium alloy can be classified from different perspectives. According to different corrosion environments, it can be divided into natural corrosion and industrial environment medium corrosion. By the type of corrosive media, it is divided into atmospheric corrosion, water corrosion and soil corrosion. When it comes to the mechanism of corrosion process, corrosion occurs by chemical corrosion and electrochemical corrosion. According to the type of corrosion morphology, it can be divided into total corrosion and local corrosion. Local corrosion also includes galvanic corrosion ${ }^{[106,107]}$, pitting corrosion ${ }^{[108]}$, stress corrosion $^{[109-111]}$, fatigue corrosion, intergranular corrosion and hydrogen induced cracking (Fig. 3) ${ }^{[112]}$.

Magnesium alloy is widely used as a kind of light metal structure material while poor corrosion resistance becomes its worst disadvantage. Corrosion often occurs in the hidden parts which are not easy to be detected, which will reduce the strength, plasticity and toughness of magnesium alloy, and then lead to the failure of structural materials. For instance, "catastrophic corrosion", such as bridge fracture, oil and gas pipeline explosion, will bring huge economic loss and even personal harm. It is of great significance to study the factors affecting the corrosion of magnesium alloy for controlling the corrosion behavior of alloy and effectively avoiding or reducing the occurrence of corrosion.

\section{Basic principle of wettability}

\subsection{Theoretical study on wettability of superhydro phobic surfaces}

Neinhuis ${ }^{[113]}$ and Barthlott ${ }^{[114]}$ carried out a large amount of research on water-repellent plant and found that there were micron-grade raised rough structures and wax layer on the surface of the plant. Feng et al. ${ }^{[115]}$ researched the "Lotus-Effect" and explored that the true secret of the superhydrophobic effect of the lotus leaf surface was the micro-nano composite structure on the lotus leaf surface. The bumps of the two sizes were compounded with each other, so that the surface of the lotus leaf had good hydrophobic property ${ }^{[116]}$. Researchers fabricated bio-inspired water-repellent surface with superhydrophobic property by mimicking the micro-nano papilla structure of lotus leave (Fig. 4). In addition, they defined the superhydrophobic surface and identified two key factors to obtain the surface: one is to construct a complex micro/nano rough structure, and the other is to modify the surface with low surface energy materials $^{[117,118]}$.

For the qualitative analysis of the wettability of liquid drops on solid surfaces, the size of contact angle (CA) of water drops is an important indicator to determine the wettability of the surface. Wettability can be divided into four types according to the CA: superhydrophilic surfaces $\left(\mathrm{CA} \leq 5^{\circ}\right)$, hydrophilic surfaces $\left(5^{\circ} \leq\right.$ $\left.\mathrm{CA} \leq 90^{\circ}\right)$, and hydrophobic surfaces $\left(90^{\circ} \leq \mathrm{CA} \leq 150^{\circ}\right)$, and superhydrophobic surfaces $\left(\mathrm{CA} \geq 150^{\circ}\right)^{[119-121]}$.

The Wenzel model and Cassie-Baxter model are commonly used to analyze and explain the mechanism of solid superhydrophobic surfaces with different adhesion behaviors ${ }^{[122-124]}$, as shown in Fig. 5a. Wenzel introduced the $\gamma$ dimensionless surface roughness factor as a modification of the Young's equation ${ }^{[125]}$.

$$
\cos \theta^{\prime}=\frac{\gamma\left(\sigma_{\mathrm{SV}}-\sigma_{\mathrm{SL}}\right)}{\sigma_{\mathrm{LV}}}=\gamma \cos \theta,
$$

where $\gamma$ is the ratio of the actual surface area to the apparent area. As the value of $\gamma$ is greater than 1, the surface roughness structure has a strengthening effect on the wettability.

The Cassie-Baxter model is similar to the wetting state of water droplets on the surface of lotus leaves in nature ${ }^{[126]}$, and exhibits a surface characteristic of low adhesion, as shown in Fig. 5b. When the surface composite contact reaches equilibrium, the applicable solid surface wetting equation is deduced from the thermodynamic angle $e^{[127,128] \text { : }}$

$$
\cos \theta=f_{1} \cos \theta_{1}+f_{2} \cos \theta_{2},
$$

where $f_{1}$ and $f_{2}$ represent the area fraction of solid-liquid and liquid-gas interface contact at the solid interface, $\theta_{1}$ and $\theta_{2}$ represent the intrinsic contact angles of the solid-liquid and liquid-gas interface. For liquid-gas-solid three-phase compound interface equilibrium, that is, $\theta_{2}=180^{\circ}, f_{1}+f_{2}=1$, substituting into Eq. (4) can deduce: 


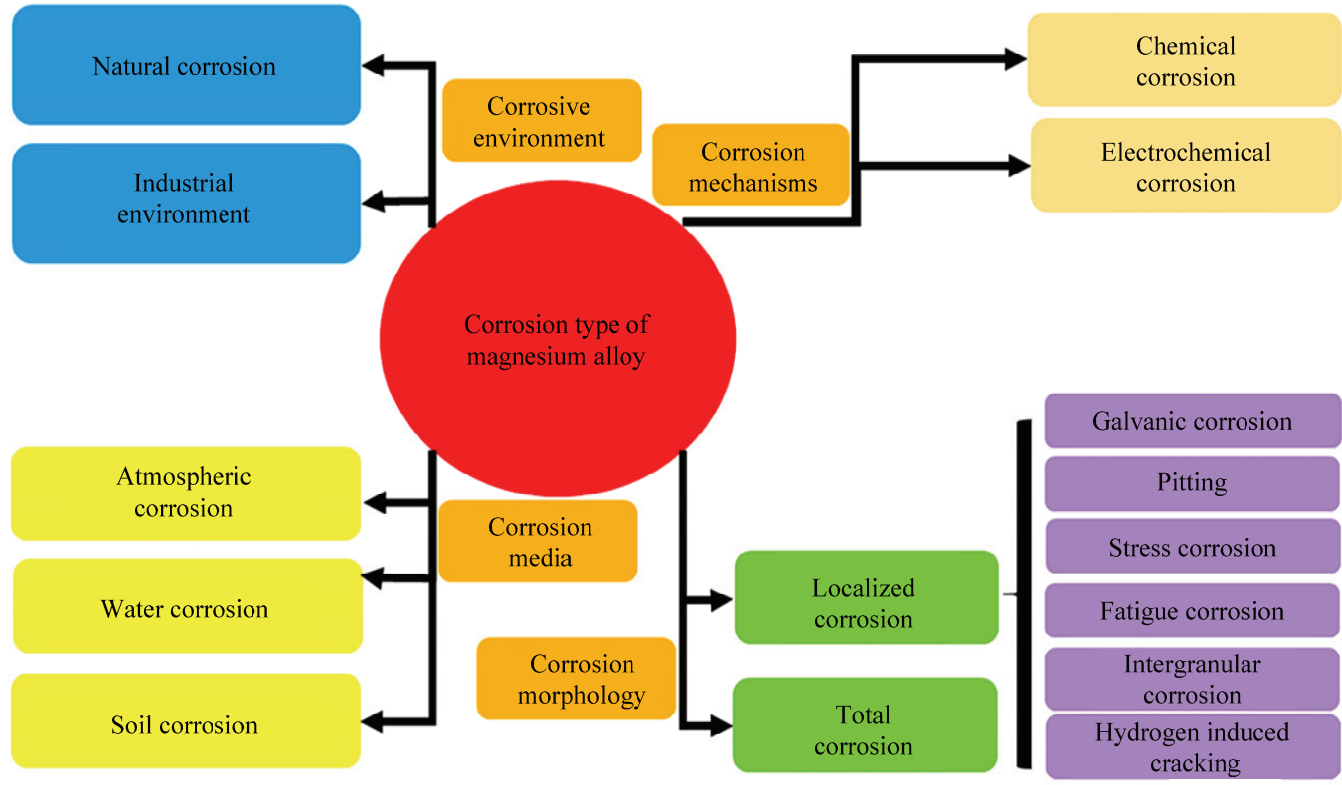

Fig. 3 Corrosion types of magnesium alloy.

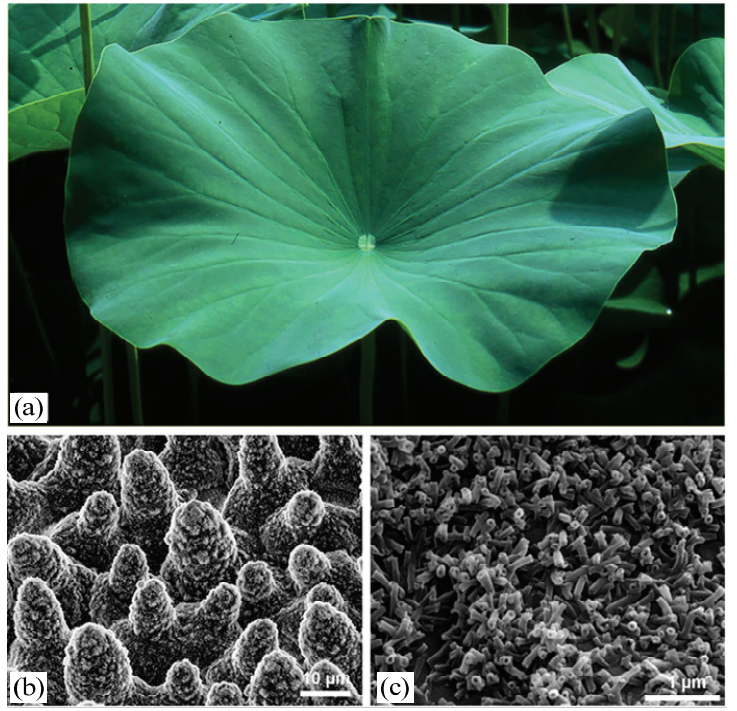

Fig. 4 (a) Superhydrophobic lotus leaf surface, (b) and (c) SEM photographs of the lotus leaf surface at different magnification $^{[117]}$.

$$
\cos \theta=f_{1}\left(\cos \theta_{1}+1\right)-1 .
$$

When the solid surface roughness increases, it is beneficial to increase the contact area between the liquid and the air film at the liquid-solid contact interface. Some scholars have found that during the preparation of superhydrophobic surfaces of magnesium alloys, the corrosion resistance of the Cassie state (low adhesion) on the superhydrophobic surface is better than that of the
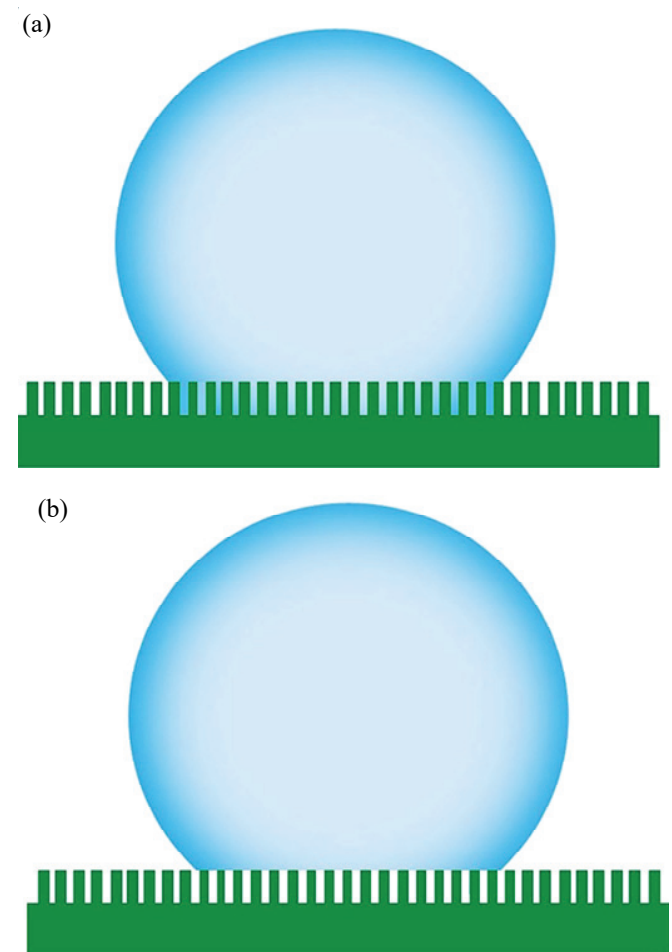

Fig. 5 Schematic diagram of wetting condition. (a) Wenzel model; (b) Cassie model.

Wenzel state (high adhesion) on the superhydrophobic surface. High-adhesion superhydrophobic surfaces have a larger contact area with liquids than low-adhesion superhydrophobic surfaces ${ }^{[129]}$. A large amount of air present on the low-adhesion superhydrophobic surfaces 
(Cassie state) acts as an air cushion, which can prevent the corrosion solution from directly eroding the magnesium alloy ${ }^{[130]}$ (Fig. 6).

\subsection{Theoretical study on wettability of SLIPSs}

Inspired by pitcher plants in nature (Figs. 7a-7e), bio-inspired slippery surface means the surface with certain lubrication effect achieved by lubricating liquid filling ${ }^{[131]}$. The new bio-inspired surface has emerged in recent years and exhibited special surface wettability, so it is a derivative exploration of superhydrophobic surfaces. Wong et al. ${ }^{[132]}$ first proposed "SLIPS" in 2011, and gave three criteria for designing SLIPS: first, lubricating oil can penetrate into the rough structure of solid-phase substrate to wet the solid-phase substrate, and realize the solid combination of the two. Second, in order not to be replaced by other liquids, the solid phase substrate should be wetted by lubricating oil preferentially. Third, the lubricating oil and the tested liquid must not be mutually soluble (Fig. 7f).

Aiming to meet the second principle, the lubricant and solid-phase substrate must be matched in physical and chemical properties so as to form a solid working system. Moreover, the lubricating oil is not compatible with the test liquid. The surface energy of the solid-liquid interface is $E_{\mathrm{a}}$ when the test liquid thoroughly wets the solid substrate. When the test liquid floats on the top and the lubricant completely wets the solid phase substrate, the surface energy of the solid-liquid interface is $E_{\alpha}$. When no test liquid floats on the top and the lubricant thoroughly wets the solid substrate, the surface energy of the solid-liquid interface is $E_{\beta}$. In order to ensure that the solid phase substrate is preferentially wetted by the lubricating oil, and the lubricating oil stored in the microstructure is not replaced by the test liquid, $\Delta E_{\alpha}=E_{\mathrm{a}}-E_{\alpha}>0$ and $\Delta E_{\beta}=E_{\mathrm{a}}-E_{\beta}>0$ must be met.

Preston et al. ${ }^{[133]}$ and Anand et al. ${ }^{[134]}$ focused on the first and second principles and analyzed the characteristics of porous substrates filled with lubricating oil with different surface energies. In summing up the failed design cases, it was found that there were five types of failures caused by the interaction between the oil layer and the test liquid (Fig. 8): first, the surface energy of the oil layer was too low, the "cloaks" phenomenon of the

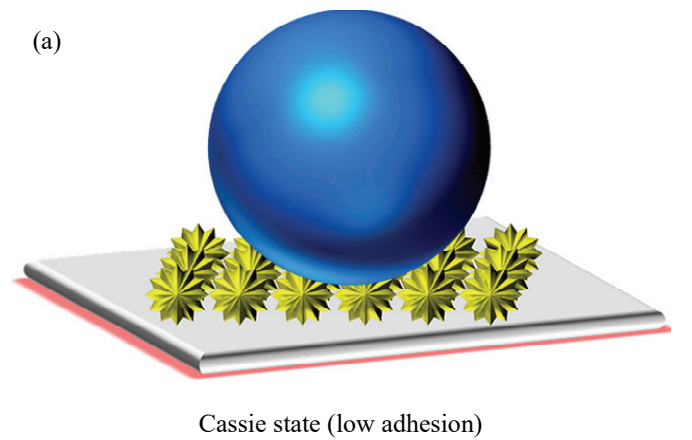

(b)

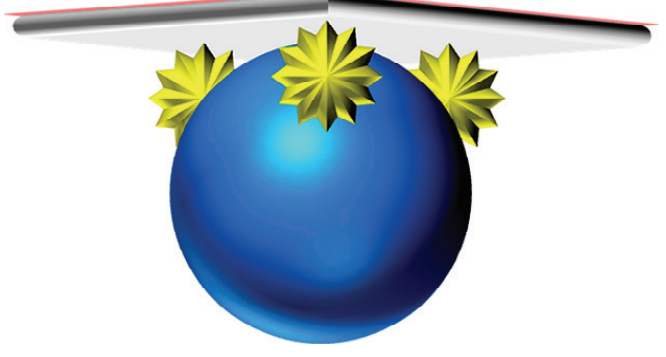

Wenzel state (high adhesion)

Fig. 6 (a) Cassie state; (b) Wenzel state ${ }^{[130]}$.

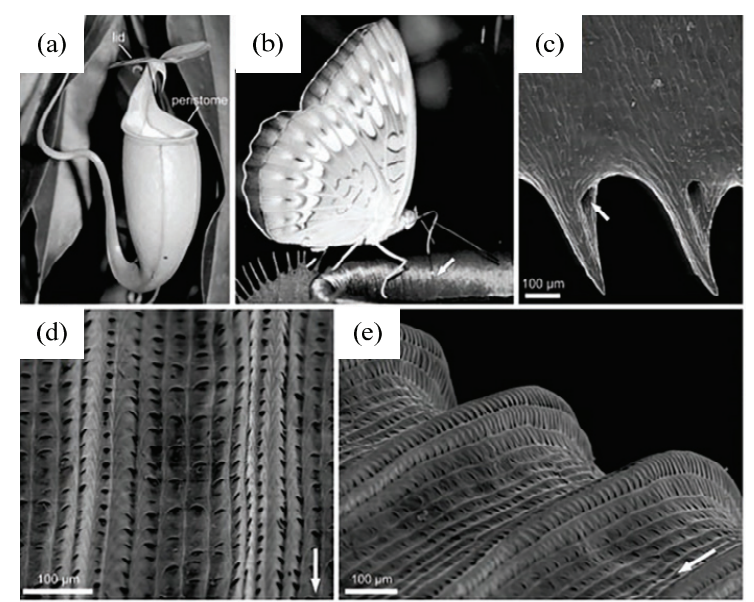

(f)

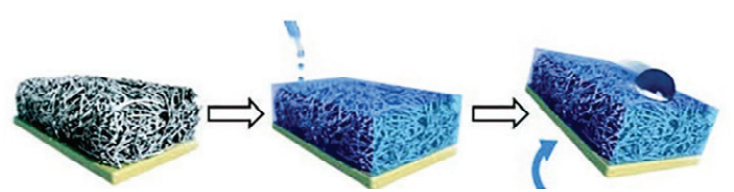

Fig. 7 (a-e) nepenthes pitcher and peristome morphology ${ }^{[131]}$; (f) schematic illustration of fabricating the SLIPS ${ }^{[132]}$.

wrapped test liquid occurred, resulting in the gradual loss of oil layer. Second, the surface energy of the lubricating oil was high, and the test liquid could not condense into droplets and slide down. Third, the oil layer failed to completely wet the rough substrate 
(a)

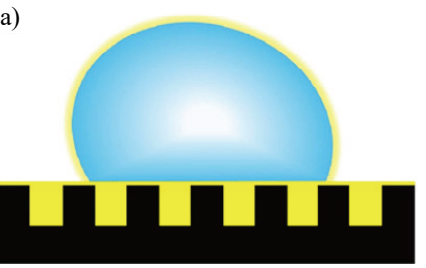

(c)

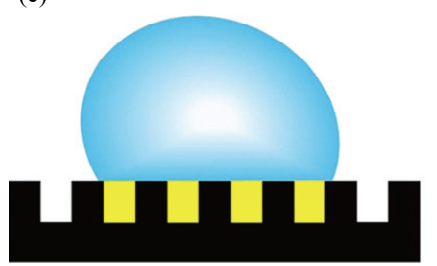

(b)

(d)

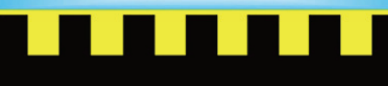

(e)

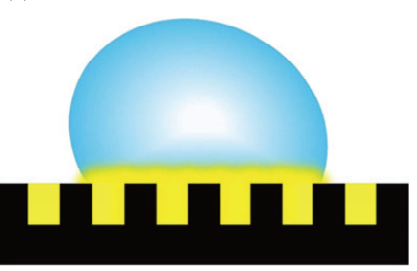

Fig. 8 Five failure types of SLIPS surface: (a) cloak phenomenon; (b) external media spread on SLIPS surface; (c) partial infusion of lubricant into porous substrate; (d) penetration of external liquid into substrate; (e) miscibility of lubricant and external liquid ${ }^{[133]}$.

surface. Fourth, part of the oil layer was replaced by the test liquid. Fifth, the oil layer was miscible with the test liquid. In short, the SLIPS design must satisfy the following 5 formulas:

The oil layer will not "cloak" the test liquid:

$$
S_{\mathrm{ol}(\mathrm{v})}=\gamma_{\mathrm{lv}}-\gamma_{\mathrm{lo}}-\gamma_{\mathrm{ov}}<0 .
$$

The test liquid cannot be completely spread on the surface of the oil layer:

$$
S_{\mathrm{lo}(\mathrm{v})}=\gamma_{\mathrm{ov}}-\gamma_{\mathrm{lo}}-\gamma_{\mathrm{lv}}<0 .
$$

The oil layer can completely wet the substrate:

$$
S_{\mathrm{os}(\mathrm{v})}=\gamma_{\mathrm{sv}}-\gamma_{\mathrm{os}}-\gamma_{\mathrm{ov}}>-\gamma_{\mathrm{ov}} R \text {. }
$$

The oil layer can still spread on the surface of the substrate in the test liquid environment:

$$
S_{\mathrm{os}(1)}=\gamma_{\mathrm{ls}}-\gamma_{\mathrm{os}}-\gamma_{\mathrm{lo}}>-\gamma_{\mathrm{lo}} R
$$

The oil layer and the test liquid are not miscible:

$$
\gamma_{\text {lo }}>0
$$

where $S$ is the spreading coefficient, $\gamma$ is the surface tension, s, o, v, 1 are the solid substrate, lubricating oil, gas environment and test liquid respectively, $R$ is the roughness index.

\section{Preparation technology of magnesi- um-based bio-inspired superhydropho- bic surface}

Bio-inspired superhydrophobic surfaces have gradually become a new idea to solve the problem of poor corrosion resistance of metal materials due to their unique interface characteristics and advantages ${ }^{[135-137]}$. The existence of superhydrophobic coating can effectively cut off the direct contact of corrosive media such as humid air and corrosive solution to the magnesium alloy substrate, thereby improving the corrosion resistance of magnesium alloy and expanding its applications in the industrial field. In the past decades, researchers have proposed various methods to prepare magnesium alloys with superhydrophobic property, such as hydrothermal method ${ }^{[138,139]}$, laser processing method $^{[130,140]}$, micro-arc oxidation ${ }^{[141-143]}$, electrochemical deposition $^{[144-148]}$, anodic oxidation ${ }^{[149-151]}$, dipping method $^{[152-154]}$, chemical etching ${ }^{[155,156]}$, and solution deposition method ${ }^{[157-159]}$ (Fig. 9). Table 2 summarizes the innovative technologies applied to the surface processing of magnesium alloys.

\subsection{Hydrothermal method}

Hydrothermal treatment is achieved by placing the precursor in an autoclave and making it react at high temperature and pressure conditions. The equipment required for this treatment is simple and easy to operate, and the energy-efficient and low-cost process can occur at high temperature and pressure conditions and be used in a wide range of applications. Besides, the nanoscale materials treated by this process exhibit high purity, crystallinity and dispersibility and are controllable in morphology ${ }^{[192]}$. Li et al. ${ }^{[193]}$ prepared a 
Table 2 Summary on the processing methods of superhydrophobic magnesium alloys for corrosion resistance

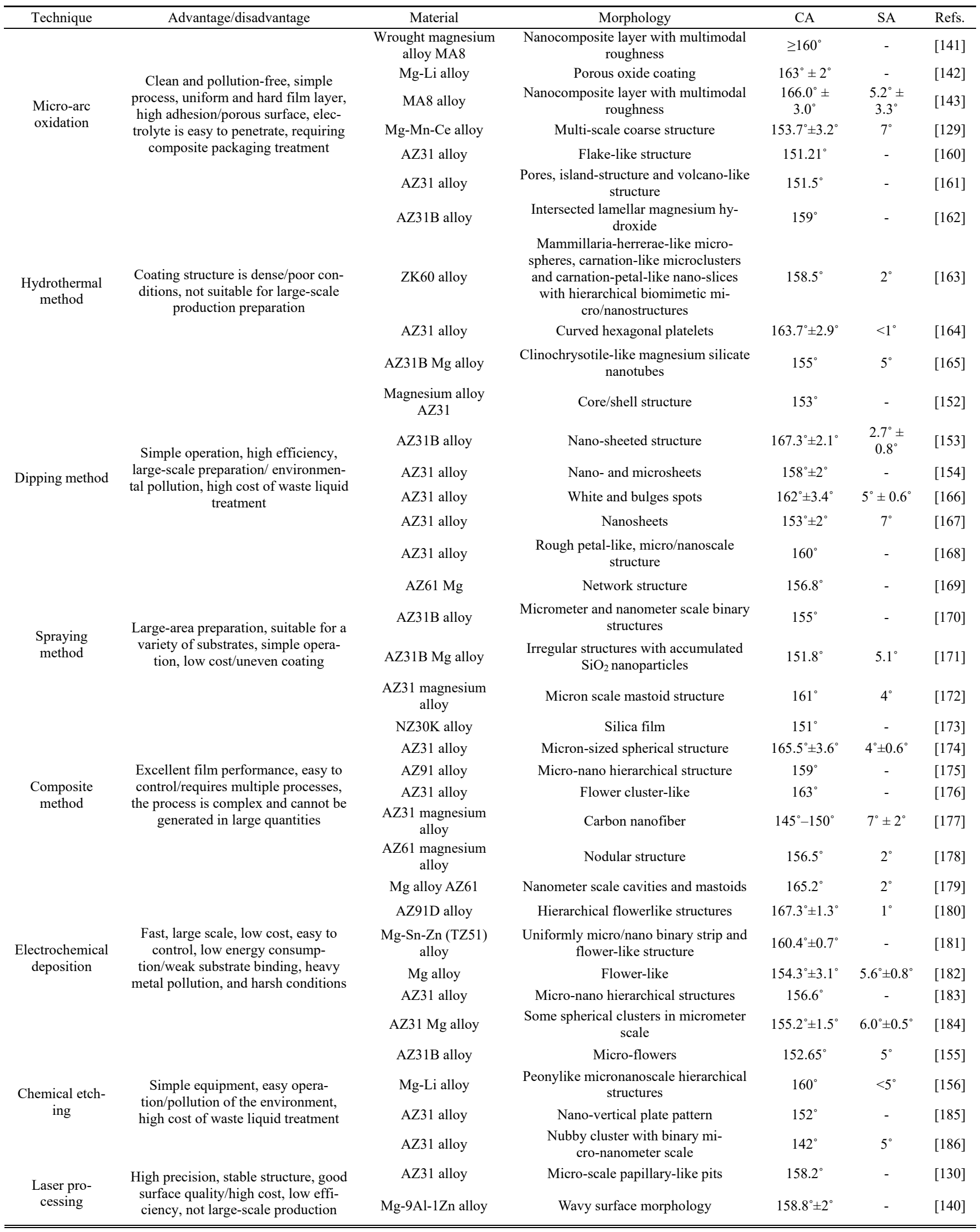




\begin{tabular}{|c|c|c|c|c|c|c|}
\hline \multirow{3}{*}{ Anodic oxidation } & \multirow{3}{*}{$\begin{array}{l}\text { One-time film formation, strong adhesion, } \\
\text { excellent abrasion resistance, low } \\
\text { cost/environmental pollution, large brit- } \\
\text { tleness, porous, difficult to process com- } \\
\text { plex workpieces }\end{array}$} & $\begin{array}{l}\text { TZ51 magnesium } \\
\text { alloy }\end{array}$ & Pits and crack & $163^{\circ}$ & - & [149] \\
\hline & & AZ31 Mg alloy & $\begin{array}{l}\text { Micro- and nano-scale } \\
\text { binary structures }\end{array}$ & $153^{\circ}$ & - & [150] \\
\hline & & AZ91D alloy & Filamentous structure & $>150^{\circ}$ & - & [151] \\
\hline \multirow{3}{*}{$\begin{array}{l}\text { Solution deposi- } \\
\text { tion }\end{array}$} & \multirow{3}{*}{$\begin{array}{l}\text { Easy operation, low cost, large-scale } \\
\text { preparation/polluting the environment, } \\
\text { high cost of waste liquid treatment }\end{array}$} & AZ31 alloy & Plate structure & $150.5^{\circ}$ & - & [157] \\
\hline & & AZ31 alloy & $\begin{array}{l}\text { Flake-like morphology } \\
\text { with nano-sized thick- } \\
\text { ness }\end{array}$ & $151.5^{\circ}$ & - & [158] \\
\hline & & AZ31 alloy & Foamed tremella & $153^{\circ}$ & $4^{\circ}$ & [159] \\
\hline \multirow{3}{*}{$\begin{array}{l}\text { Conversion } \\
\text { coating }\end{array}$} & \multirow{3}{*}{$\begin{array}{l}\text { Simple operation, low cost/environmental } \\
\text { pollution, high cost of waste liquid treat- } \\
\text { ment, uneven and brittle film, porous, easy } \\
\text { to form cracks }\end{array}$} & AZ31B alloy & Island-like platforms & $157^{\circ}$ & - & [187] \\
\hline & & $\mathrm{Mg}-\mathrm{Zn}-\mathrm{Ca}$ alloy & $\begin{array}{l}\text { Lump-like mi- } \\
\text { cro-clusters }\end{array}$ & $159^{\circ}$ & - & [188] \\
\hline & & AZ91D alloy & Microspheres & $160.19^{\circ}$ & $1.5^{\circ}$ & [189] \\
\hline \multirow{2}{*}{$\begin{array}{l}\text { Wire electrical } \\
\text { discharge ma- } \\
\text { chining (WEDM) }\end{array}$} & \multirow{2}{*}{$\begin{array}{l}\text { Low cost, high efficiency, high removal } \\
\text { efficiency of electro-corrosion prod- } \\
\text { ucts/relatively large electrode wire vibra- } \\
\text { tion, low accuracy of the machined surface, } \\
\text { and serious material waste }\end{array}$} & AZ91D magnesium & $\begin{array}{l}\text { Big etching pits, mi- } \\
\text { cro/nanopits, debris } \\
\text { particles, pores and } \\
\text { microcracks }\end{array}$ & $146^{\circ}-150^{\circ}$ & - & [190] \\
\hline & & $\begin{array}{l}\text { AZ31B magnesium } \\
\text { alloy }\end{array}$ & $\begin{array}{l}\text { Micro-/nano petal-like } \\
\text { structure }\end{array}$ & $151^{\circ} \pm 0.5^{\circ}$ & $4^{\circ} \pm 0.5^{\circ}$ & [191] \\
\hline
\end{tabular}

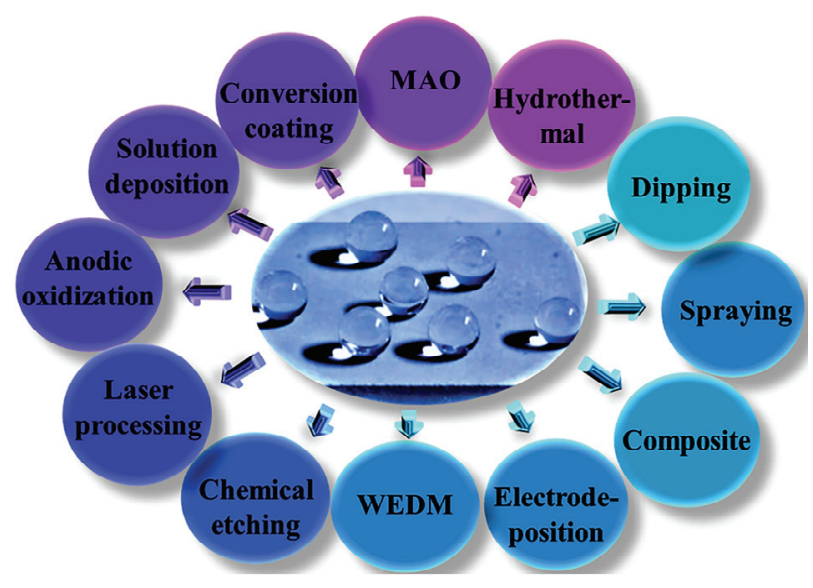

Fig. 9 Schematic diagram of various methods for preparing superhydrophobic surface ${ }^{[188]}$.

superhydrophobic coating with chemical stability and durability on the surface of AZ31 magnesium alloy by hydrothermal synthesis method. The static water contact angle was $156.7^{\circ}$, and the superhydrophobicity could be maintained for more than one year when exposed to air. In addition, the superhydrophobic coating in $3.5 \mathrm{wt} \%$ $\mathrm{NaCl}$ solution had good corrosion resistance. Zhang et al. ${ }^{[194]}$ prepared a $\mathrm{Mg}(\mathrm{OH})_{2} / \mathrm{Mg}$-Al composite coating on the AZ31 alloy substrate by co-deposition and hydrothermal methods. The surface was modified by stearic acid, and the maximum static contact angle was $153.5^{\circ}$, and the superhydrophobic surface showed good stability in electrochemical test, hydrogen evolution test and immersion test, significantly improving the corrosion resistance of AZ31 alloy (Fig. 10). But even so, this technique requires to be carried out at high temperature and pressure conditions, and therefore equipment must meet a number of strict requirements, which inhibits the development and application of the hydrothermal method in more fields. Moreover, it is not feasible for mass production due to poor preparation conditions and technical difficulties ${ }^{[195,196]}$.

\subsection{Electrochemical deposition method}

Electrochemical deposition is a simple and efficient method to prepare superhydrophobic surfaces on magnesium alloy, which relies on the reduction reaction of cathode to deposit metal or composite layer on the surface of material ${ }^{[197-199]}$. Cui et al. ${ }^{[200]}$ prepared

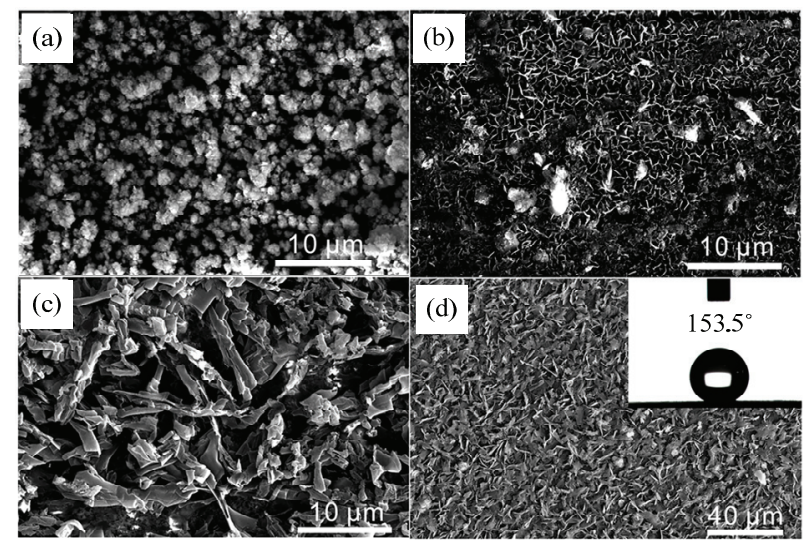

Fig. 10 SEM morphology of the sample after 14 days of immersion test. (a) AZ31; (b) LDH coating; (c) LDH/SA1 coating; (d) SEM morphology and contact angle (inset) of LDH/SA1 coating ${ }^{[194]}$. 
superhydrophobic micro-arc oxidation/zinc stearate (MAO/ZnSA) coating with micro plate-like structure on Mg-4Li-1Ca alloy by electrochemical deposition method, and the static contact angle was $153.5^{\circ} \pm 0.5^{\circ}$. The superhydrophobicity of the MAO/ZnSA composite coating effectively sealed the surface of MAO, and hence prevented the contact between the corrosion solution and the substrate, significantly enhancing the corrosion resistance of the Mg-4Li-1Ca alloy (Fig. 11). Li and Kang ${ }^{[201]}$ prepared superhydrophobic a coating on AZ31 magnesium alloy by electrochemical deposition and surface modification. The static contact angle and sliding angle were $156.2^{\circ} \pm 0.6^{\circ}$ and $1.0^{\circ}$. Superhydrophobic coatings showed excellent corrosion resistance and chemical stability when immersed in $3.5 \mathrm{wt} \% \mathrm{NaCl}$ solution and corrosive liquids. After $900 \mathrm{~mm}$ and $1100 \mathrm{~mm}$ mechanical wear tests, the coating maintained superhydrophobic property and corrosion resistance.
The process can be achieved by employing compact equipment and simple process flow in a short cycle with high metal deposition rate, and is feasible for mass production because it is a low-cost, energy-efficient and easy-to-control method. On the other hand, the film obtained by this process shows weak cohesion strength with the substrate, and in addition to this, heavy metal pollution and adverse manufacturing conditions are unavoidable problems during processing ${ }^{[202,203]}$.

\subsection{Micro-arc oxidation}

Micro-arc oxidation (MAO), also known as micro-plasma oxidation or anodic activation deposition, is a surface modification technology that produces ceramic coatings on metal surfaces. By controlling the micro-arc oxidation electrical parameters and the electrolyte system, coatings with different morphologies and structures could be prepared. The prepared ceramic coating had
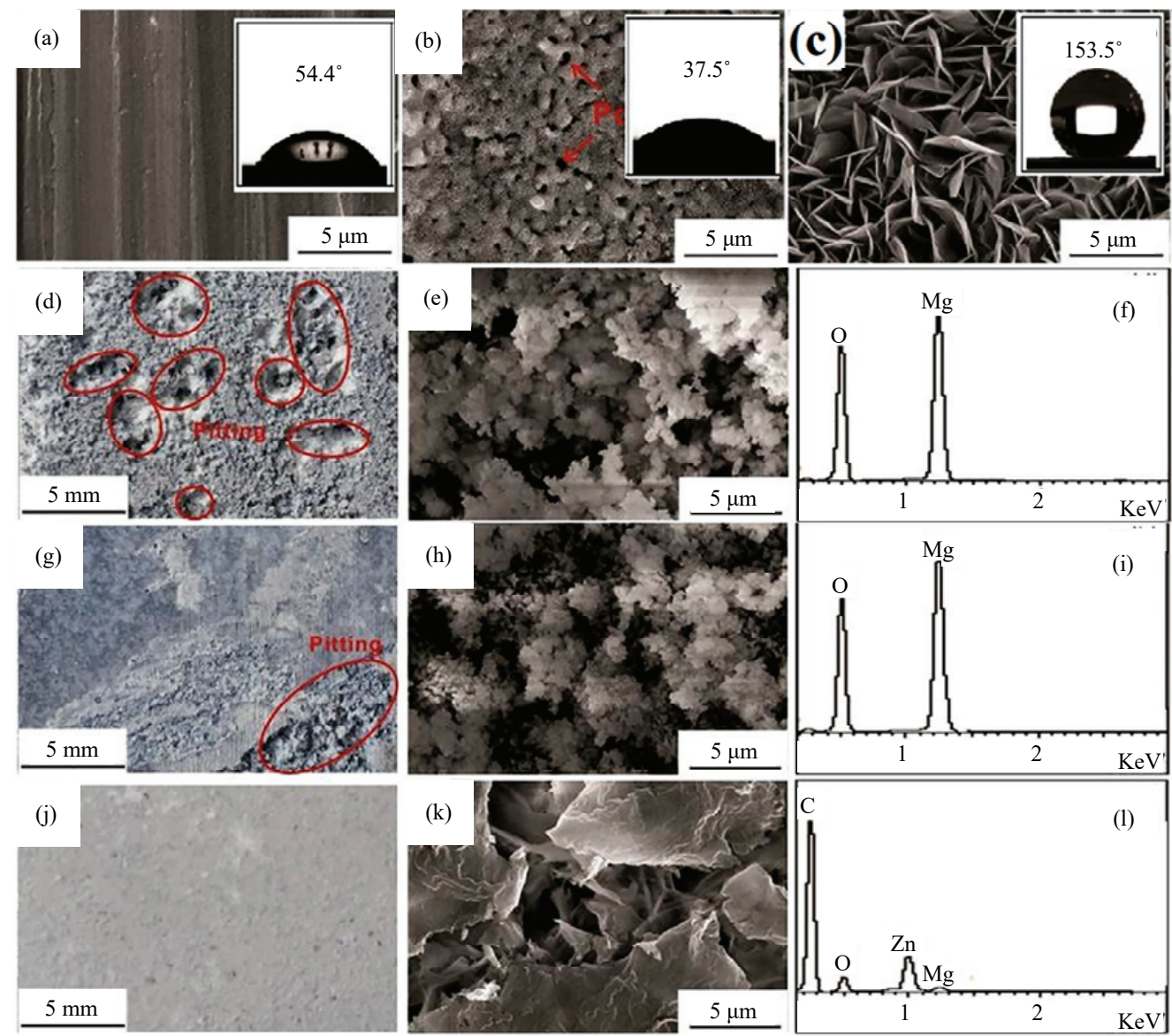

Fig. 11 SEM morphology and CA (inset) of the sample before immersion test. (a) Mg-4Li-1Ca, (b) MAO, (c) MAO/ZnSA coating. Macrograph, scanning electron microscope and energy spectrum of the sample after the 85 -hour immersion test. $(\mathrm{d}-\mathrm{f}) \mathrm{Mg}-4 \mathrm{Li}-1 \mathrm{Ca}$, $(\mathrm{g}-\mathrm{i}) \mathrm{MAO},(\mathrm{j}-\mathrm{l}) \mathrm{MAO} / \mathrm{ZnSA}$ coating ${ }^{[200]}$. 
the advantages of high hardness, good wear resistance and strong corrosion resistance ${ }^{[204,205]}$. Zhang et al. ${ }^{[206]}$ prepared a superhydrophobic coating on the surface of Mg-1Li-1Ca alloy by MAO and stearic acid modification, and the static contact angle was $155.5^{\circ}$ (Fig. 12a). In the potentiodynamic polarization, EIS, and $3.5 \mathrm{wt} \%$ $\mathrm{NaCl}$ solution immersion tests, the $\mathrm{MAO} / \mathrm{SA}-7 \mathrm{~h}$ coating showed excellent corrosion resistance and the corrosion current density was significantly reduced (Figs.12b 12e). Liu and $\mathrm{Xu}^{[207]}$ prepared an $\mathrm{AZ31}$ magnesium alloy superhydrophobic coating in a stearic acid ethanol solution using a two-step method of MAO and superhydrophobic treatment. The static contact angle of the surface was $156.96^{\circ}$. Compared with the AZ31 alloy substrate, the corrosion current density of the superhydrophobic AZ31 alloy was reduced by several orders of magnitude, the amount of hydrogen evolution was greatly reduced, and the corrosion resistance was obviously improved.

\subsection{Spraying method}

Spraying method is a technology that the coating particles impact the alloy substrate at high speed and then deposit on the alloy surface by aerodynamic force. Li et al. ${ }^{[208]}$ sprayed a fluorine-free suspension on a magnesium alloy substrate to prepare a strong superhydrophobic coating, and the contact angle and sliding angle were $159.5^{\circ}$ and $3.8^{\circ}$ (Fig. 13a). After a series
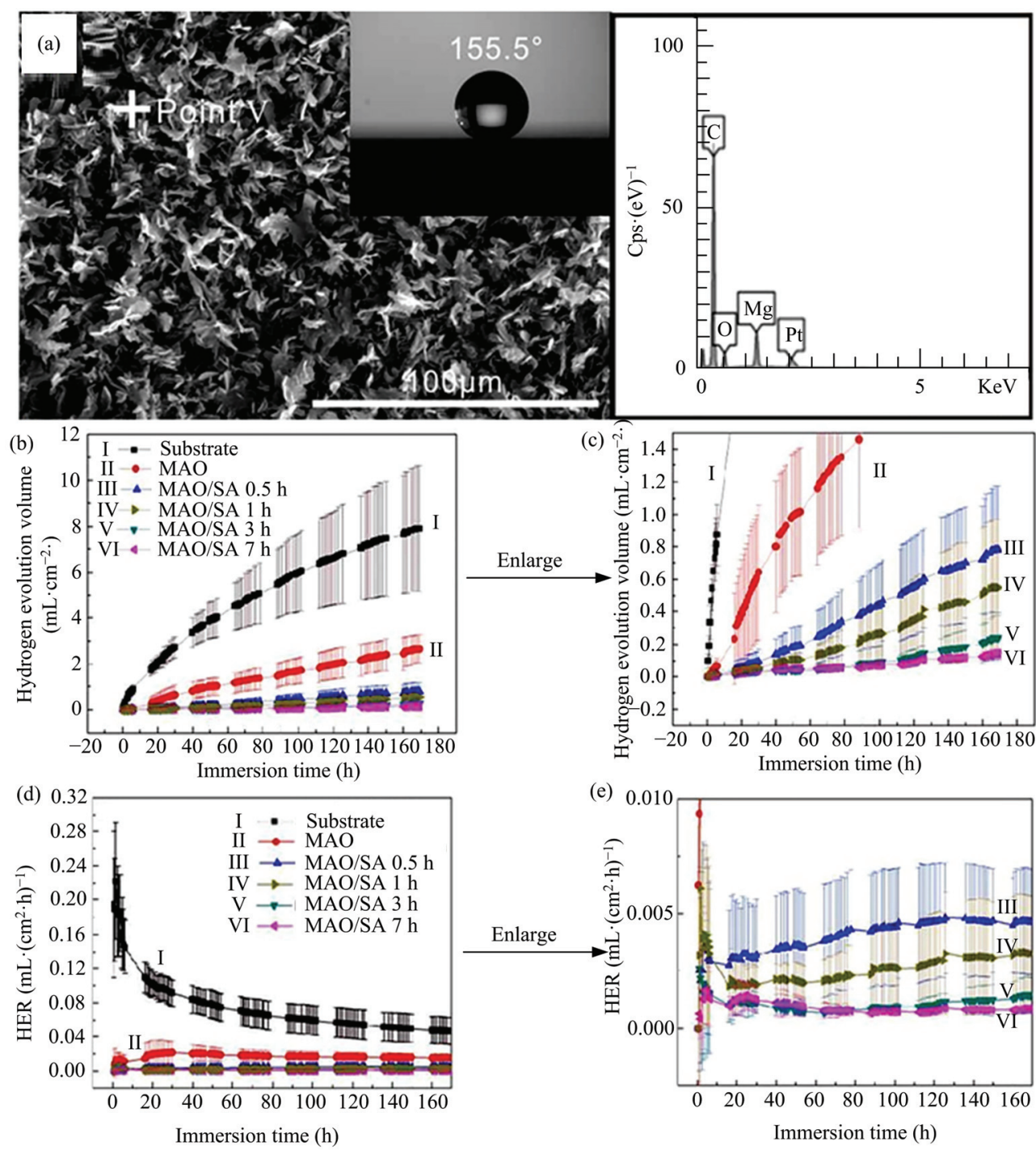

Fig. 12 (a) SEM morphology and CA (inset) of MAO/SA7h coating; (b) hydrogen evolution volume and (c) the corresponding enlarged view; (d) hydrogen evolution rates and (e) the corresponding enlarged view. (I) Mg-1Li-1Ca substrate; (II) MAO coating and (III) $\mathrm{MAO} / \mathrm{SA} 0.5 \mathrm{~h}, \mathrm{MAO} / \mathrm{SA} 1 \mathrm{~h}, \mathrm{MAO} / \mathrm{SA} 3 \mathrm{~h}, \mathrm{MAO} / \mathrm{SA} 7 \mathrm{~h}$ coatings (IV-VI) ${ }^{[206]}$. 
of mechanical damage tests and exposure to harsh environmental conditions, the coating still maintained good superhydrophobicity. In addition, the coating exhibited excellent self-cleaning performance and corrosion resistance in air and oil (Fig. 13b), and self-healing resistance to $\mathrm{O}_{2}$ plasma etching (Figs. $13 \mathrm{c}$ and 13d). Shi et al. ${ }^{[209]}$ prepared a polyphenylene sulfide-polytetrafluoroethylene/ $\mathrm{SiO}_{2} \quad$ (PPS-PTFE/ $/ \mathrm{SiO}_{2}$ ) coating on the AZ31 magnesium alloy by spraying. The morphology, composition, contact angle, abrasion behavior and corrosion performance of the composite coating were tested by scanning electron microscopy, infrared spectroscopy, contact angle test, abrasive paper wear, and electrochemical tests. The static contact angle of PPS-PTFE $/ \mathrm{SiO}_{2}$ coating was in the range of $\left(152^{\circ}-145.5^{\circ}\right) \pm 0.3^{\circ}$, and the sliding angle was less than $5^{\circ}$. PPS-PTFE $/ \mathrm{SiO}_{2}$ coating had good abrasion resistance and excellent corrosion resistance. This process is an environmentally friendly and easy-to-use means of preparing large area coating on different types of substrates with low cost. However, uneven coating occurs during the spraying process, and hazards exist that pose a potential danger to operators' health ${ }^{[210,211]}$.

\subsection{Dipping method}

The superhydrophobic surface can be obtained directly by immersing the magnesium alloy into the solution, so the surface that used this method does not need to be modified with low surface energy materials again, which is beneficial to the rapid and large-scale production of superhydrophobic surfaces ${ }^{[212]}$. Xun et al. ${ }^{[213]}$ prepared a coating with low adhesion and superhydrophobic properties on the surface of AZ31B alloy by a two-step in-situ dipping method. The coating had good mechanical stability and ultra-low water adhesion, which gave AZ31B alloy excellent corrosion resistance (Fig. 14). In addition, compared with the AZ31B substrate, the coating had anti-bioadhesion properties, which greatly reduced the adhesion of biomolecules (proteins, bacteria and cells). Ishizaki et al.${ }^{[214]}$ prepared myristic acid modified micro/nano structure on the surface of AZ31 alloy by one-step dipping method, and the
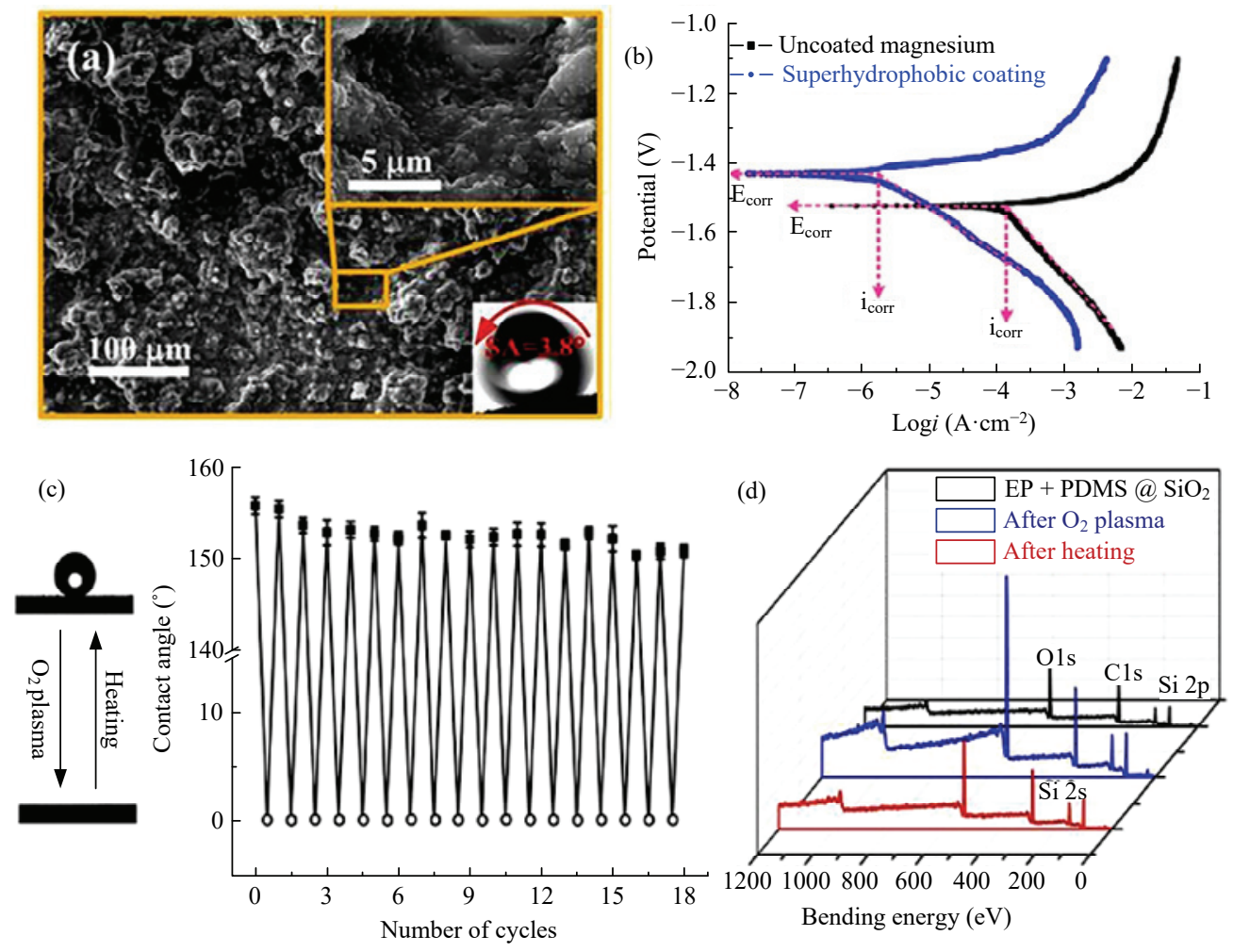

Fig. 13 (a) SEM morphology and rolling angle (inset) of EP+PDMS@ $\mathrm{SiO}_{2}$ coating, (b) potential polarization curves of magnesium alloy substrate and EP+PDMS@SiO 2 coating, (c) self-healing cycles of superhydrophobic coating, (d) XPS analysis of EP+PDMS@SiO2 coating during self-healing ${ }^{[208]}$. 
(a)
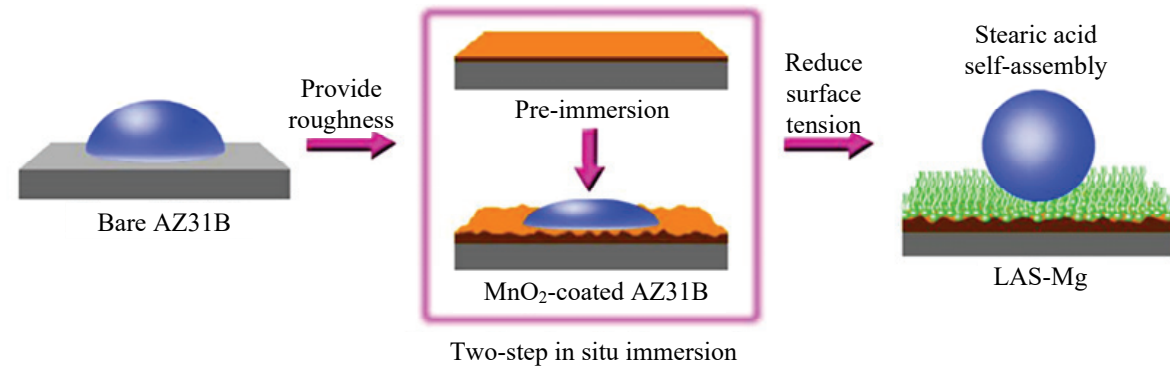

(b)

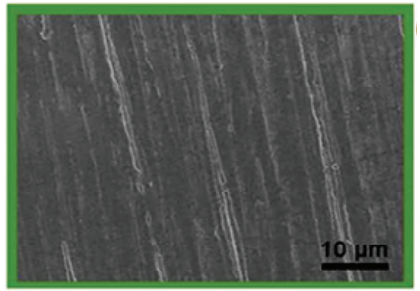

(d)

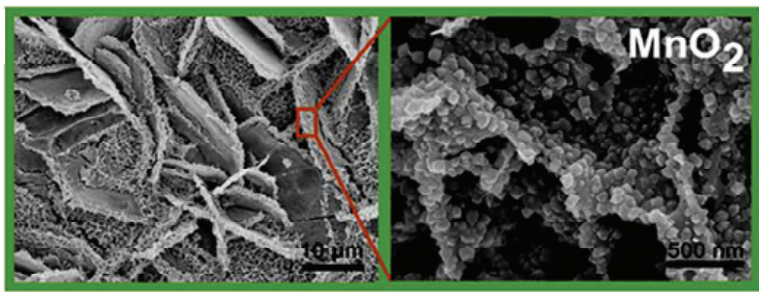

(c)
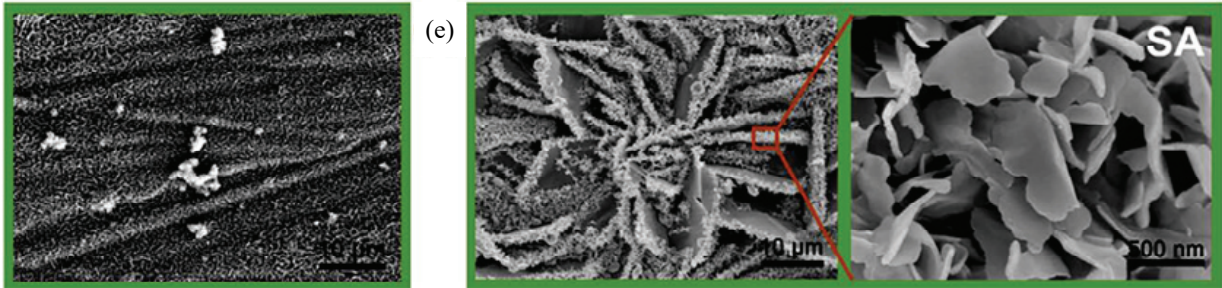

Fig. 14 SEM morphology of the LAS-Mg superhydrophobic coating during its preparation. (a) process flow diagram, (b) AZ31B substrate, (c) pre-immersed AZ31B, (d) $\mathrm{MnO}_{2}$-coated AZ31B, (e) LAS Mg ${ }^{[213]}$.

static contact angle of the surface was more than $150^{\circ}$. The superhydrophobic samples were immersed into solutions of $\mathrm{pH} \mathrm{4,} 7$ and 10 for $12 \mathrm{~h}$, and the average static contact angles were $90^{\circ} \pm 2^{\circ}, 119^{\circ} \pm 2^{\circ}$, and $138^{\circ} \pm$ $2^{\circ}$, indicating that superhydrophobic coatings had certain chemical stability. Besides, the superhydrophobic coatings showed good corrosion resistance in electrochemical test.

\subsection{Chemical etching}

Chemical etching method is a manufacturing process that uses strong acid, strong base or concentrated salt solution to remove materials from magnesium alloys to produce rough micro/nano structures ${ }^{[215,216]}$. Feng et $a l{ }^{[217]}$ prepared a superhydrophobic coating on the surface of AZ91 magnesium alloy by using sulfuric acid etching, $\mathrm{AgNO}_{3}$ treatment, and dodecyl mercaptan modification. The water contact angle and sliding angle were $154^{\circ}$ and $5^{\circ}$. Electrochemical experiments showed that superhydrophobic surfaces had good corrosion resistance. Wang et al. ${ }^{[218]}$ used chemical etching to generate nano-scale three-dimensional porous structures on the surface of AZ31 magnesium alloy (Fig. 15e), and made the surface superhydrophobic by oleic acid modification to obtain a coating with a static water contact angle of $155^{\circ}$ (Figs. 15b and 15d). The air cushion effect in the superhydrophobic coating effectively isolated the contact between the corrosive medium and the substrate (Fig. 15c), resulting in improved corrosion resistance of the magnesium alloy substrate. After 6 months of storage in the air, it still demonstrated a good superhydrophobicity (Fig. 15f). Advantages of this process are that it is easy and simple and doesn't require complicated equipment for etching, and capable of producing surface textures with good controllability without applying current and voltage. However, waste stream generated from the process poses dangers to the environment and witnesses high chemical disposal costs ${ }^{[219,220]}$.

\subsection{Wire electrical discharge machining}

Wire Electrical Discharge Machining (WEDM) is one of the nontraditional machining processes for removing the material from the workpiece surface by using a continuous moving wire electrode which is usually 
(a)

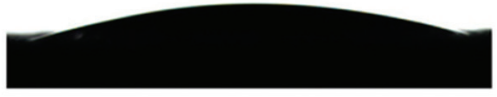

(d)

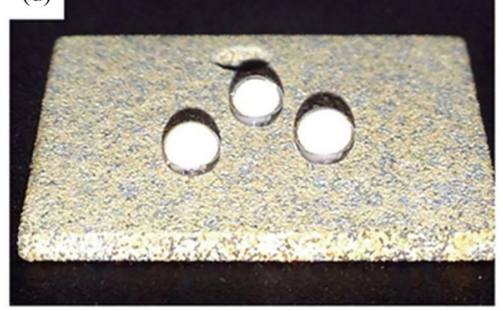

(b)

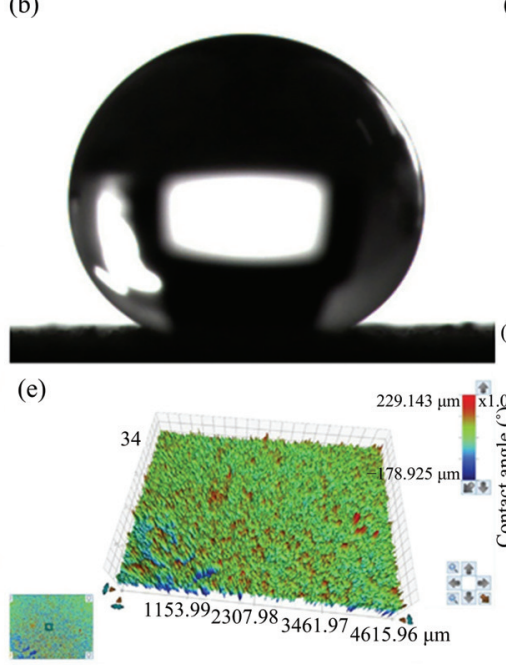

(c)

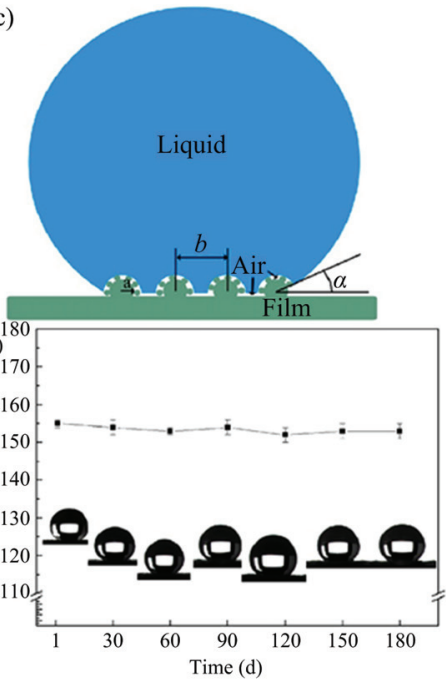

Fig. 15 (a) Static contact angle of magnesium alloy surface, (b) static contact angle of superhydrophobic coating, (c) superhydrophobic diagram, (d) superhydrophobic coating, (e) a 3D profile scanning image of superhydrophobic coating, (f) effect of changes in air storage time on contact angle ${ }^{[218]}$.

made of copper or molybdenum as a machining tool electrode to establish a discharge channel via the application of impulse voltage between positive and negative electrodes of the workpiece and the wire electrode backed by the pulsed power supply of the machine tool. Making use of the instantaneous high temperature induced in the discharge channel by collisions of charged particles, the material on the surface melts and vaporizes, resulting in removal of material from the workpiece $^{[221,222]}$. Xu et al.$^{[190]}$ studied the influence of the number of power tubes on the performance of a workpiece surface by machining an AZ91D magnesium alloy using a high-speed wire electrical discharge machine (WEDM-HS). The results showed that the surface treated by WEDM-HS was covered with a carbon layer and exhibited high hydrophobicity (the contact angle range between $146^{\circ}$ and $150^{\circ}$ ). Moreover, an increase in the number of power tubes caused the micro-pits and cracks on the surface of the magnesium alloy to be reduced and resulted in improved corrosion resistance. Qiu et al.$^{[191]}$ fabricated a superhydrophobic surface with micro-nano petal-like structure on an AZ31B magnesium alloy by combining WEDM-HS process and surface modification method, with a contact angle and a sliding angle of $151^{\circ}$ $\pm 0.5^{\circ}$ and $4^{\circ} \pm 0.5^{\circ}$, respectively (Fig. 16). The experimental results indicated that the superhydrophobic surface exhibited excellent corrosion resistance and wear resistance, and the corrosion current density decreased by almost an order of magnitude. During the friction-wear test, the superhydrophobic surface demonstrated a lower coefficient of friction. WEDM is a low-cost and highly efficient option for manufacturing as well as has high efficiency in removing electro-corrosion products while violent vibration of the electrode wire, low accuracy of the machined surface and serious material waste are problems to be addressed ${ }^{[223,224]}$.

\subsection{Composite method}

The composite method is essentially a combination of two or more processing methods to obtain a micro-nano structure superhydrophobic coating on the surface of the magnesium alloy ${ }^{[225-227]}$. The two or more methods are used together in order to combine best properties and make the prepared coatings easy to control and exhibit stronger superhydrophobicity and durability than those fabricated by a single processing method. Zang et al. ${ }^{[228]}$ prepared a bio-inspired lotus seed-like superhydrophobic coating on the surface of AZ91D alloy by a combination of hydrothermal synthesis and sonication assisted electroless plating. The static water contact angle was $153.9^{\circ} \pm 2.7^{\circ}$, and the sliding angle was less than $5^{\circ}$. The superhydrophobic coating had good corrosion resistance, which could effectively isolate the corrosion solution and protect the 

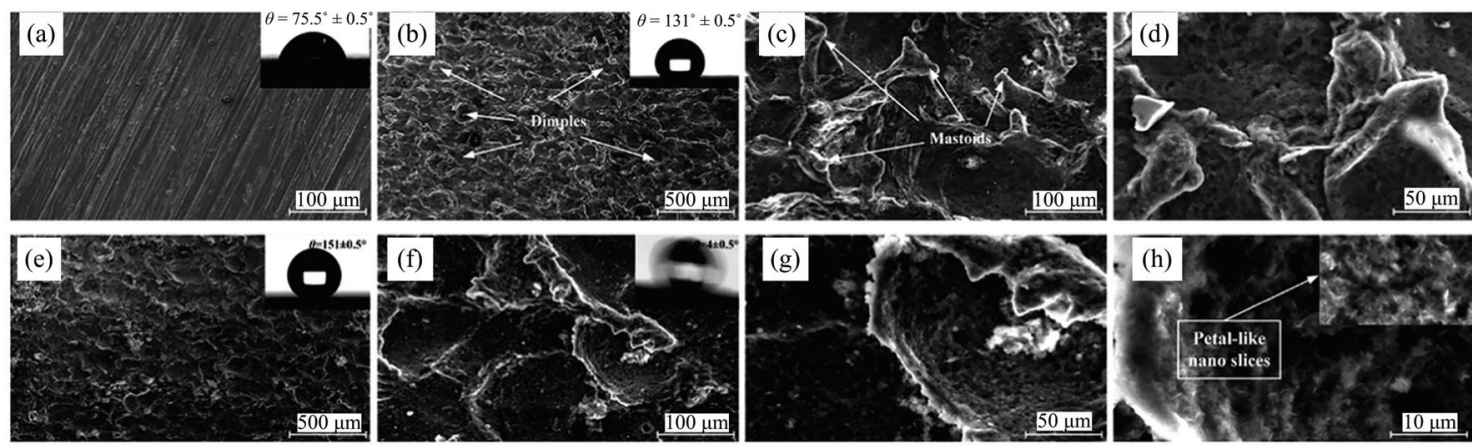

Fig. 16 Scanning electron microscope morphologies and water contact angle (inset) of (a) the bare magnesium alloy, (b - d) the high-speed wire electrical discharge machining (HS-WEDM) surface, and (e - h) the HS-WEDM/stearic acid composite surface ${ }^{[191]}$.

magnesium alloy substrate. Superhydrophobic coatings showed thermally induced reversible wetting transitions between superhydrophilic and superhydrophobic states, and had excellent fatigue resistance (Fig. 17). Ding et $a l .{ }^{[229]}$ prepared an anti-corrosion coating with superhydrophobic and self-repairing on the surface of AZ31B magnesium alloy by hydrothermal synthesis and spraying. The static water contact angle of the composite coating was $163^{\circ}$. The chemical test, immersion method and scanning vibrating electrode method were used to study the corrosion resistance of the coating. Compared with Layer Double Hydroxides (LDHs) coatings, superhydrophobic composite coatings had good corrosion resistance, durability and self-healing properties, which is of great significance for expanding the potential applications of magnesium alloys.

\section{Preparation technology of magnesi- um-based SLIPS}

In practical applications, it is found that the superhydrophobic property of superhydrophobic coating is not stable, which will lead to the failure of superhydrophobic coating under high temperature, high pressure or surface damage ${ }^{[230]}$. Based on the bio-inspired principle, the researchers studied the special surface properties of the pitcher's mouth area, and synthesized a SLIPS by injecting a low-surface-energy lubricant into the micro/nano-structured substrate ${ }^{[231-233]}$. SLIPS lubricants can effectively isolate the corrosion of the substrate by the corrosive medium. Especially in the liquid, the lubricants and the aqueous solution are incompatible with each other, and can be stored for a long time, which has a long-term protection potential for the substrate to reduce corrosion $^{[234-236]}$. Table 3 summarizes the innovative technologies applied to the surface processing of magnesium alloys.

SLIPS repels liquids based on the lubricating fluid layer and solid substrate with special microstructure. The solid substrate with special microstructure firmly locks the lubricating liquid layer, and the low-surface-energy lubricating liquid layer has a repellent effect on the liquids. The liquids have a larger contact angle and smaller contact angle hysteresis on the SLIPS $^{[245]}$.

Jiang et al. ${ }^{[238]}$ used plasma electrolytic oxidation

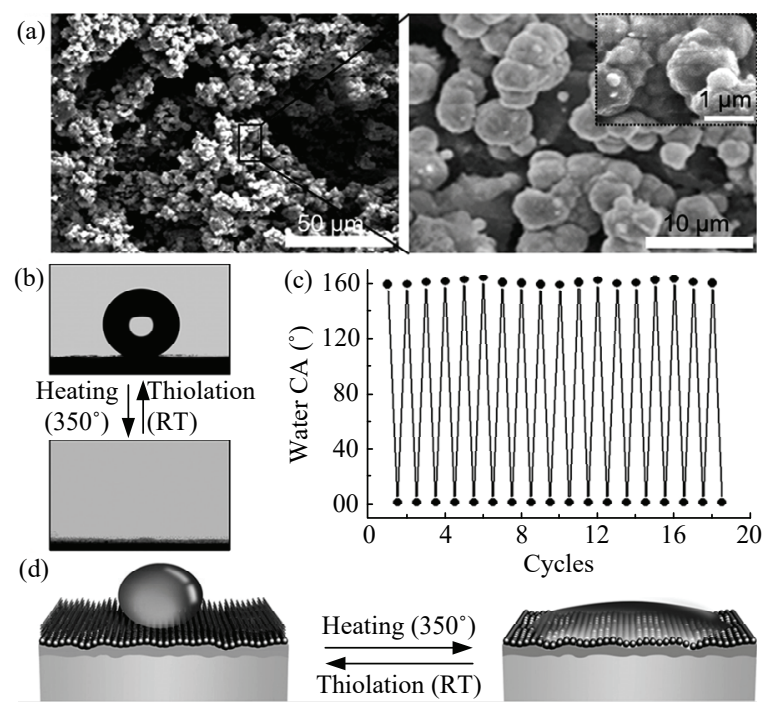

Fig. 17 (a) SEM morphology of the superhydrophobic coating after heating; (b) wettability process of superhydrophobic coating; (c) contact angle measurements after a transition period, (d) schematic diagram of the wettability transition of a superhydrophobic coating ${ }^{[228]}$. 
Table 3 Summary on the processing methods of SLIPS on magnesium alloys for corrosion resistance

\begin{tabular}{|c|c|c|c|c|c|}
\hline Technique & Advantage/disadvantage & Material & $\mathrm{CA}$ & $\mathrm{CAH}$ & Refs. \\
\hline \multirow{5}{*}{$\begin{array}{l}\text { Hydrothermal meth- } \\
\text { od }\end{array}$} & \multirow{5}{*}{$\begin{array}{l}\text { Coating structure is dense/ poor conditions, } \\
\text { not suitable for large-scale production prepa- } \\
\text { ration }\end{array}$} & AZ31B magnesium alloy & $123.1^{\circ}$ & $2.7^{\circ}$ & [237] \\
\hline & & AZ91D magnesium alloy & $121^{\circ}$ & - & [238] \\
\hline & & AZ31B magnesium alloy & $122^{\circ}$ & $12^{\circ}$ & [239] \\
\hline & & AZ31 magnesium alloy & $105^{\circ}$ & $3^{\circ}$ & [240] \\
\hline & & AZ31B Mg alloy & $115^{\circ}$ & - & [241] \\
\hline Anodic treatment & $\begin{array}{l}\text { Simple operation, low cost /environmental } \\
\text { pollution, high cost of waste liquid treatment }\end{array}$ & Magnesium alloy & $117^{\circ}$ & $8^{\circ}$ & [242] \\
\hline \multirow{2}{*}{ Spraying method } & \multirow{2}{*}{$\begin{array}{c}\text { Large-area preparation, suitable for a variety } \\
\text { of substrates, simple operation, low } \\
\text { cost/uneven coating }\end{array}$} & Magnesium alloy AZ31B & $\leq 110^{\circ}$ & $\leq 10^{\circ}$ & [243] \\
\hline & & AZ31B magnesium alloy & $106^{\circ} \pm 1.0^{\circ}$ & - & [244] \\
\hline
\end{tabular}

method and hydrothermal method to generate MgAl-LDH coating on the surface of AZ91D alloy, and chemically modified and injected lubricant to prepare PEO-LDH-SLIPS. In the immersion test and electrochemical test, the PEO-LDH-SLIPS showed long-term water-repellency and self-healing ability of surface damage. The water-repellency and self-healing properties made the AZ91D magnesium alloy have excellent corrosion resistance (Fig. 17). Zhang et al. ${ }^{[239]}$ used a hydrothermal method to form a barrier layer on the surface of AZ31B alloy, chemically modified and injected lubricant to prepare a double-layer anti-icing and corrosion resistant SLIPS. Compared with superhydrophobic coatings, SLIPSs had smaller rolling angles, long-lasting corrosion resistance and anti-icing performance. Zhang et al. ${ }^{[242]}$ anodized the magnesium alloy in the choline chloride-ethylene glycol based deep eutectic solvent, changed the external anode current density, and formed a conversion film with porous network and jagged nanorod arrays on the surface of the magnesium alloy. After surface modification and injection of lubricating oil, superhydrophobic surface and SLIPSs were obtained. In the electrochemical test, superhydrophobic surface and SLIPSs exhibited better corrosion resistance.

\section{Summary and outlook}

The corrosion resistance of magnesium alloy is extremely poor, which severely restricts its application range in different fields. Improving the corrosion resistance of magnesium alloy has become an urgent problem that needs to be solved. This article summarizes the research progress on corrosion resistance of magnesium alloys with bio-inspired water-repellent properties in recent years. By analyzing the factors and types of corrosion affecting magnesium alloys, based on the bio-inspired principle, the superhydrophobic surface and SLIPS are prepared on the surface of magnesium alloy to improve the corrosion resistance of magnesium alloy. Nevertheless, during the preparation and application of the magnesium-based bio-inspired water-repellent surfaces, there are still many problems to be solved:

(1) The bio-inspired superhydrophobic surface of magnesium alloy has gradually become a new idea to solve the problem of poor corrosion resistance of magnesium alloy due to its unique interface characteristics and advantages. As mentioned earlier, various processing technologies for constructing superhydrophobic coatings on the surface of magnesium alloys have been proposed, but these technologies still face some problems that need to be solved urgently. For example, the micro-arc oxidation method causes high power consumption, produces a porous surface, and requires a composite packaging treatment. The hydrothermal method has poor preparation conditions and is not suitable for large-scale production. Volatile organic solvents are used in spraying method, which is harmful to human body and creates uneven coating. The preparation process of the composite method is complex and unsuitable for mass production. In the electrochemical deposition method, the adhesion between the film and the substrate is weak and the heavy metal pollution will occur. The dipping method/chemical etching method/solution deposition/conversion coating all can pollute the environment and the cost of waste liquid treatment is high. Laser processing technology is costly and inefficient. The surface accuracy of WEDM is low and the material waste is serious. The anodized film is 


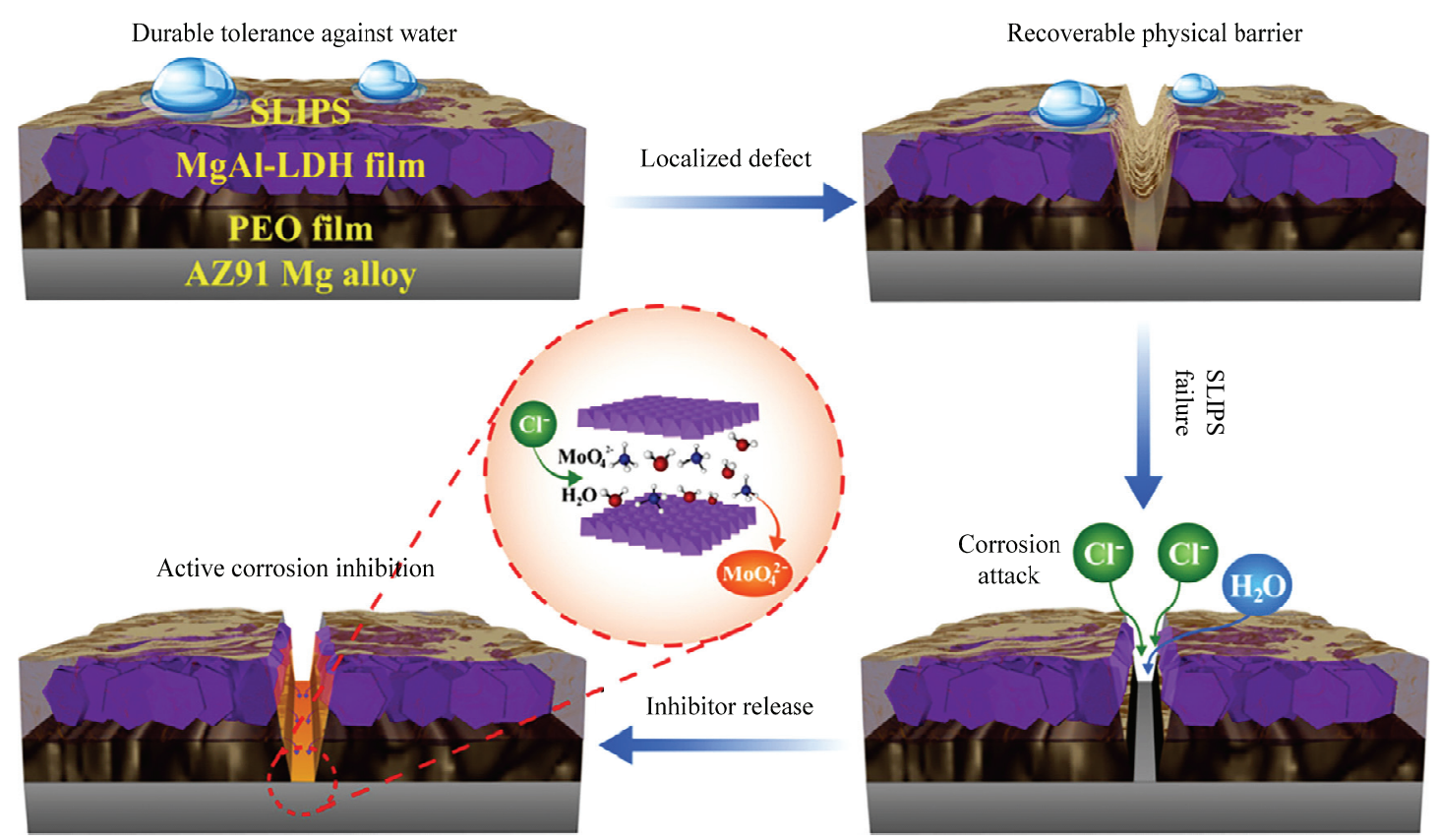

Fig. 18 Schematic protection mechanism for the smart anticorrosion system on $\mathrm{Mg}$ alloy ${ }^{[238]}$.

brittle and porous, making it difficult to process complex workpieces.

(2) Superhydrophobic coating has a wide application in the fields of improving corrosion resistance of magnesium alloys due to its unique properties. On the other hand, some issues still need to be addressed such as high manufacturing cost and limited large-scale production. Furthermore, low-surface-energy modifiers used during manufacturing are expensive, and fluorine-containing substances such as fluoroalkyl silanes and fluoroacrylic copolymers pose significant risks to human health and the environment. In addition, it is found in the practical application of the superhydrophobic coating that its superhydrophobicity was not stable and failed at high temperatures and pressures, or on damaged surface. It is thus considered to be of great significance to develop environmentally friendly, cost-effective and efficient modifiers and to design simple but effective manufacturing process ensuring superhydrophobic coating with self-healing performance on the surface of magnesium alloys can be obtained.

(3) Compared with the superhydrophobic surface, SLIPS has more excellent corrosion resistance and durability, but there are still some problems in the prepa- ration process of SLIPS. The microstructure of the substrate surface is too simple to store lubricant adequately, and the processing technology is unsuitable for large-scale preparation because of its complex operations and long cycle time. Besides, problems such as expensive lubricant, volatile lubricant and poor durability still need to be solved. To solve this problem and extend the service life and create greater value of SLIPS in practical applications, researchers have tried to produce regular-shaped nanostructures by increasing the complexity of the surface microstructure, and have considered replacing liquid lubricants by solid ones. So far, there are few studies on the preparation of SLIPSs magnesium alloys, which needs to be further promoted and studied.

(4) Both superhydrophobic surface and SLIPS can effectively improve the corrosion resistance of magnesium alloy and extend its service life, making it possible to speed up production and use of magnesium alloy in various fields, but there are some problems that still have not been solved. Since the environment in practical applications is complex and diverse, the corrosion resistance of magnesium alloys is more demanding. Especially in biomedical and industrial production, the corrosion resistance and biocompatibility of magnesium 
alloys need to be considered comprehensively. Therefore, the application research and development technology of magnesium alloy with multi-functional needs to be urgently proposed.

\section{Acknowledgment}

This work was supported by the National Key Research and Development Program of China (No. 2018YFB1107403), the National Natural Science Foundation of China (No. U19A20103), the China Postdoctoral Science Foundation (No. 2019M661184), the Jilin Province Scientific and Technological Development Program (No. Z20190101005JH), and the "111" Project of China (No. D17017).

Open Access This article is licensed under a Creative Commons Attribution 4.0 International License, which permits use, sharing, adaptation, distribution and reproduction in any medium or format, as long as you give appropriate credit to the original author(s) and the source, provide a link to the Creative Commons licence, and indicate if changes were made.

The images or other third party material in this article are included in the article's Creative Commons licence, unless indicated otherwise in a credit line to the material. If material is not included in the article's Creative Commons licence and your intended use is not permitted by statutory regulation or exceeds the permitted use, you will need to obtain permission directly from the copyright holder.

To view a copy of this licence, visit http://creativecommons.org/licenses/by/4.0/.

\section{References}

[1] Singh I B, Singh M, Das S. A comparative corrosion behavior of $\mathrm{Mg}, \mathrm{AZ31}$ and $\mathrm{AZ91}$ alloys in 3.5\% $\mathrm{NaCl}$ solution. Journal of Magnesium and Alloys, 2015, 3, 142-148.

[2] Pan H C, Ren Y P, Fu H, Zhao H, Qin G. Recent developments in rare-earth free wrought magnesium alloys having high strength: A review. Journal of Alloys and Compounds, 2016, 663, 321-331.

[3] Kiani M, Gandikota I, Rais-Rohani M, Motoyama, K. Design of lightweight magnesium car body structure under crash and vibration constraints. Journal of Magnesium and Alloys, 2014, 2, 99-108.

[4] Liu F J, Ji Y, Sun Z Y, Liu J B, Shen Z K. Enhancing corro- sion resistance and mechanical properties of AZ31 magnesium alloy by friction stir processing with the same speed ratio. Journal of Alloys and Compounds, 2020, 829, 154452.

[5] Rangasa V, Ramesh S, Maniraj S, Subburam $\mathrm{V}$. Measurement and multi-response optimization of turning parameters for magnesium alloy using hybrid combination of Taguchi-GRA-PCA technique. Measurement, 2020, 159, 107800.

[6] Jin S, Zhang D, Lu X, Zhang Y, Tan L, Liu Y, Wang Q. Mechanical properties, biodegradability and cytocompatibility of biodegradable $\mathrm{Mg}-\mathrm{Zn}-\mathrm{Zr}-\mathrm{Nd} / \mathrm{Y}$ alloys. Journal of Materials Science \& Technology, 2020, 47, 190-201.

[7] Ostrovsky I, Henn Y. Present state and future of magnesium application in aerospace industry. International Conference "New Challenges in Aeronautics" Astec, Moscow, Russia, 2007, 19-22.

[8] Zhao X, Gao P C, Zhang Z M, Wang Q, Yan F F. Fatigue characteristics of the extruded AZ80 automotive wheel. International Journal of Fatigue, 2019, 132, 105393.1-105393.12.

[9] Wu F, Zhang S, Tao Z. Corrosion behavior of 3C magnesium alloys in simulated sweat solution. Materials and Corrosion-Werkstoffe and Korrosion, 2015, 62, 234-239.

[10] Zomorodian A, Garcia M P, Silva T M E, Fernandes J C S, Fernandes M H, Montemor M F. Corrosion resistance of a composite polymeric coating applied on biodegradable AZ31 magnesium alloy. Acta Biomater, 2013, 9, $8660-8670$.

[11] Bommala V K, Krishna M G, Rao C T. Magnesium matrix composites for biomedical applications: A review. Journal of Magnesium and Alloys, 2018, 7, 72-79.

[12] Li S B, Yang X Y, Hou J T, Du W B. A review on thermal conductivity of magnesium and its alloys. Journal of Magnesium and Alloys, 2020, 8, 78-90.

[13] Singh K, Singh G, Singh H. Review on friction stir welding of magnesium alloys. Journal of Magnesium and Alloys, 2018, 6, 399-416.

[14] Mordike B L, Ebert T. Magnesium properties-applications-potential. ACS Biomaterials Science \& Engineering, 2001, 302, 37-45.

[15] Li Z G, Yang H F, Liu J G. Comparative study on yield behavior and non-associated yield criteria of AZ31B and ZK61 M magnesium alloys. ACS Biomaterials Science \& Engineering, 2019, 759, 329-345.

[16] Atrens A, Johnston S, Shi Z, Dargusch M S. Viewpoint-understanding $\mathrm{Mg}$ corrosion in the body for biodegradable medical implants. Scripta Materialia, 2018, 154, 
92-100.

[17] Esmaily M, Mortazavi N, Svensson J E, Halvarsson M, Jarfors A E W, Wessén M, Arrabal R, Johansson L G. On the microstructure and corrosion behavior of AZ91/SiC composites produced by rheocasting. Materials Chemistry and Physics, 2016, 180, 29-37.

[18] Hagihara K, Okubo M, Yamasaki M, Nakano T. Crystal-orientation-dependent corrosion behaviour of single crystals of a pure $\mathrm{Mg}$ and $\mathrm{Mg}-\mathrm{Al}$ and $\mathrm{Mg}-\mathrm{Cu}$ solid solutions. Corrosion Science, 2016, 109, 68-85.

[19] Seifiyan H, Sohi M H, Ansari M, Ahmadkhaniha D, Saremi $\mathrm{M}$. Influence of friction stir processing conditions on corrosion behavior of AZ31B magnesium alloy. Journal of Magnesium and Alloys, 2019, 7, 605-616.

[20] Ali M, Elsherif M, Salih A E, Ul-Hamid A, Hussein M A, Park S, Butt H. Surface modification and cytotoxicity of Mg-based bio-alloys: An overview of recent advances. Journal of Alloys and Compounds, 2020, 825, 154140.

[21] Peng J, Zhang Z, Long C, Chen H, Wu Y, Huang J, Zhou W, Wu Y. Effect of crystal orientation and $\{1012\}$ twins on the corrosion behaviour of AZ31 magnesium alloy. Journal of Alloys and Compounds, 2020, 827, 154096.

[22] Wang Y, Liu B, Zhao X, Zhang X, Miao Y, Yang N, Yang B, Zhang L, Kuang W, Li J, Ma E, Shan Z. Turning a native or corroded $\mathrm{Mg}$ alloy surface into an anti-corrosion coating in excited $\mathrm{CO}_{2}$. Nature Communications, 2018, 9, 4058.

[23] Orlov D, Ralston K D, Birbilis N, Estrin Y. Enhanced corrosion resistance of $\mathrm{Mg}$ alloy ZK60 after processing by integrated extrusion and equal channel angular pressing. Acta Materialia, 2011, 59, 6176-6186.

[24] Zhao M, Liu M, Song G, Atrens A. Influence of the $\beta$-phase morphology on the corrosion of the Mg alloy AZ91. Corrosion Science, 2008, 50, 1939-1953.

[25] Gray J E, Luan B. Protective coatings on magnesium and its alloys-a critical review. Journal of Alloys and Compounds, 2002, 336, 88-113.

[26] Ali M, Hussein M A, Al-Aqeeli N. Magnesium-based composites and alloys for medical applications: A review of mechanical and corrosion properties. Journal of Alloys and Compounds, 2019, 792, 1162-1190.

[27] Esmaily M, Svensson J E, Fajardo S, Birbilis N, Johansson L G. Fundamentals and advances in magnesium alloy corrosion. Progress in Materials Science, 2017, 89, 92-193.

[28] Song G, Atrens A. Understanding magnesium corrosion-a framework for improved alloy performance. Advanced Engineering Materials, 2003, 5, 837-858.

[29] Abbott T B. Magnesium: Industrial and research develop- ments over the last 15 years. Corrosion, 2015, 71, 120-127.

[30] Zhang C, Wu L, Huang G S, Zhang C, Liu K, Jiang B, Wang G G, Xia D B, Atrens A, Pan F S. Influence of microalloying with $\mathrm{Ca}$ and $\mathrm{Ce}$ on the corrosion behavior of extruded Mg-3Al-1Zn. Journal of The Electrochemical Society, 2019, 166, C445-C453.

[31] Park T M, Kim H J, Um H Y, Goo N H, Han J. The possibility of enhanced hydrogen embrittlement resistance of medium-Mn steels by addition of micro-alloying elements. Materials Characterization, 2020, 165, 110386.

[32] Zheng Q J, Zhang L L, Jiang H X, Zhao J Z, He J. Effect mechanisms of micro-alloying element $\mathrm{La}$ on microstructure and mechanical properties of hypoeutectic Al-Si alloys. Journal of Materials Science \& Technology, 2020, 47, 142-151.

[33] Luo S, Su Y, Wang, Z. Tailored microstructures and strengthening mechanisms in an additively manufactured dual-phase high-entropy alloy via selective laser melting. Science China-Materials, 2020, 63, 1279-1290.

[34] Wang C Y, Chang Y, Zhou F L, Cao W Q, Dong H. M-3 microstructure control theory and technology of the third-generation automotive steels with high strength and high ductility. Acta Chimica Sinica, 2020, 56, 400-410.

[35] José S C, Luís C, Filipe R, Diogo F. The effect of surface treatment and environmental actions on the adhesive connection between GFRP laminate surface and fresh FRC. Construction and Building Materials, 2020, 258, 119594.

[36] Zheng X, Xie C C, Li W M, Aberle A G, Venkataraj S. Investigations of potassium-induced surface treatment of $\mathrm{Cu}(\mathrm{In}, \mathrm{Ga}) \mathrm{Se}_{2}$ (CIGSe) thin film solar cells prepared by two-stage process using elemental selenium. Applied Surface Science, 2020, 525, 146368.

[37] Zhang Y F, Blawert C, Tang S W, Hu J, Marta M, Zheludkevich M L, Kainer K U. Influence of surface pre-treatment on the deposition and corrosion properties of hydrophobic coatings on a magnesium alloy. Corrosion Science, 2016, 112, 483-494.

[38] Song Z W, Yu G, Xie Z H, Hu B N, He X M, Zhang X Y. Performance of composite coating on AZ31B magnesium alloy prepared by anodic polarization and electroless electrophoresis coating. Surface \& Coatings Technology, 2014, 242, 83-91.

[39] Peng C Y, Chen Z Y, Tiwari M K. All-organic superhydrophobic coatings with mechanochemical robustness and liquid impalement resistance. Nature Materials, 2018, 17, 355-360.

[40] Wu L, Wu J, Zhang Z, Zhang C, Zhang Y, Tang A, Li L, 
Zhang G, Zheng Z, Atrens A, Pan F. Corrosion resistance of fatty acid and fluoroalkylsilane-modified hydrophobic Mg-Al LDH films on anodized magnesium alloy. Applied Surface Science, 2019, 487, 569-580.

[41] Yin Z Z, Qi W C, Zeng R C, Chen X B, Gu C D, Guan S K, Zheng Y F. Advances in coatings on biodegradable magnesium alloys. Journal of Magnesium and Alloys, 2020, 8, $42-65$.

[42] Lian Z X, Xu J K, Wang Z B, Yu H D. Biomimetic superlyophobic metallic surfaces: Focusing on their fabrication and applications. Journal of Bionic Engineering, 2020, 17, $1-33$.

[43] Vazirinasab E, Jafari R, Momen G. Application of superhydrophobic coatings as a corrosion barrier: A review. Surface and Coatings Technology, 2018, 341, 40-56.

[44] Ran M R, Zheng W Y, Wang H M. Fabrication of superhydrophobic surfaces for corrosion protection: A review. Materials Science \& Technology, 2019, 35, 313-326.

[45] Zhao X, Wei J F, Li B C, Li S B, Zhang J P. A self-healing superamphiphobic coating for efficient corrosion protection of magnesium alloy. Journal of Colloid and Interface Science, 2020, 575, 140-149.

[46] Wang J, Cui L Y, Ren Y D, Zou Y H, Ma J L, Wang C J, Zheng Z Y, Chen X B, Zheng Y F. In vitro and in vivo biodegradation and biocompatibility of an MMT/BSA composite coating upon magnesium alloy AZ31. Journal of Materials Science \& Technology, 2020, 47, 52-67.

[47] Chen J F, Liang S Y, Fu D B, Fan W X, Lin W X, Ren W W, Zou L C, Cui X P. Design and in situ prepare a novel composite coating on $\mathrm{Mg}$ alloy for active anti-corrosion protection. Journal of Alloys and Compounds, 2020, 831, 154580.

[48] Gao F, Hu Y D, Li G C, Liu S, Quan L, Yang Z M, Wei Y C, Pan C J. Layer-by-layer deposition of bioactive layers on magnesium alloy stent materials to improve corrosion resistance and biocompatibility. Bioactive Materials, 2020, 5, 611-623.

[49] Luque-Agudo V, Fernandez-Calderon M C, Pacha-Olivenza M A, Perez-Giraldo C, Gallardo-Moreno A M, Gonzalez-Martin M L. The role of magnesium in biomaterials related infections. Colloids and surfaces B: Biointerfaces, 2020, 191, 110996.

[50] Yang W, Zhu Z J, Wang J J, Wu Y C, Zhai T, Song G L. Slow positron beam study of corrosion behavior of AM60B magnesium alloy in $\mathrm{NaCl}$ solution. Corrosion Science, 2016, 106, 271-280.

[51] Li J, Jiang Q, Sun H, Li Y. Effect of heat treatment on corrosion behavior of AZ63 magnesium alloy in $3.5 \mathrm{wt} \%$ so- dium chloride solution. Corrosion Science, 2016, 111, 288-301.

[52] He Y Q, Peng C Q, Feng Y, Wang R C, Zhong J F. Effects of alloying elements on the microstructure and corrosion behavior of Mg-Li-Al-Y alloys. Journal of Alloys and Compounds, 2020, 834, 154344.

[53] Azzeddine H, Hanna A, Dakhouche A, Rabahi L, Baudin T. Impact of rare-earth elements on the corrosion performance of binary magnesium alloys. Journal of Alloys and Compounds, 2020, 829, 154569.

[54] Chen X R, Liao Q Y, Le Q, Zou Q, Wang H N, Atrens A. The influence of samarium ( $\mathrm{Sm})$ on the discharge and electrochemical behaviors of the magnesium alloy AZ80 as an anode for the Mg-air battery. Electrochimica Acta, 2020, 348, 136315 .

[55] He J J, Jiang B, Zhang J Y, Xiang Q, Xia X S, Pan F $\mathrm{S}$. Enhancement of mechanical properties and corrosion resistance of magnesium alloy sheet by pre-straining and annealing. Materials Science and Engineering: A, 2015, 647, 216-221.

[56] Mineta T, Sato H. Simultaneously improved mechanical properties and corrosion resistance of $\mathrm{Mg}$ - $\mathrm{Li}-\mathrm{Al}$ alloy produced by severe plastic deformation. Materials Science and Engineering: A, 2018, 735, 418-422.

[57] Wang H Y, Xue E S, Xiao W, Liu Z, Li J B, Jiang Q C. Influence of grain size on deformation mechanisms in rolled Mg-3Al-3Sn alloy at room temperature. Materials Science and Engineering: A, 2011, 528, 8790-8794.

[58] Yuan Y, Ma A B, Gou X F, Jiang J H, Arhin G, Song D, Liu $H$. Effect of heat treatment and deformation temperature on the mechanical properties of ECAP processed ZK60 magnesium alloy. Materials Science and Engineering: A, 2016, 677, 125-132.

[59] Chen W Z, Zhang W C, Qiao Y D, Miao Q, Wang E. Enhanced ductility in high-strength fine-grained magnesium and magnesium alloy sheets processed via multi-pass rolling with lowered temperature. Journal of Alloys and Compounds, 2016, 665, 13-20.

[60] Li Y J, Qin F M, Liu C R, Li L J, Wu Z S. Influence of rotation rate on microstructure and comprehensive performance of FSWed Mg alloy. Journal of Materials Engineering and Performance, 2018, 27, 5635-5643.

[61] Mao B, Liao Y L, Li B. Gradient twinning microstructure generated by laser shock peening in an AZ31B magnesium alloy. Applied Surface Science, 2018, 457, 342-351.

[62] Joshi S, Singh R C, Chaudhary R. Effect of rotational speed in friction stir processing on the microstructural and me- 
chanical characteristics of cast AS21A magnesium alloy. Materials Research Express, 2019, 6, 056554.

[63] Jiang J H, Xie Q Y, Qiang M S, Aibin M A, Taylor E K, Li Y H, Song D, Chen J Q. Stress-corrosion-cracking behaviors of RE-containing ME21 magnesium alloy processed by equal-channel angular pressing. Journal of Rare Earths, 2018, 37, 88-94.

[64] Karr U, Schönbauer B M, Mayer H. Near-threshold fatigue crack growth properties of wrought magnesium alloy AZ61 in ambient air, dry air, and vacuum. Fatigue \& Fracture of Engineering Materials \& Structures, 2018, 41, 1938-1947.

[65] Sanchez A H M, Luthringer B J C, Feyerabend F, Willumeit $\mathrm{R} . \mathrm{Mg}$ and $\mathrm{Mg}$ alloys: How comparable are in vitro and in vivo corrosion rates? A review. Acta Biomaterialia, 2015, 13, 16-31.

[66] Liu H G, Cao F Y, Song G L, Zheng D J, Shi Z M, Dargusch M S, Atrens A. Review of the atmospheric corrosion of magnesium alloys, Journal of Materials Science \& Technology, 2019, 35, 2003-2016.

[67] Zhao Z X, Hua Z M, Li D W, Wei D S, Liu Y, Wang J G, Wang H Y. Effect of Sn content on the microstructure, mechanical properties and corrosion behavior of biodegradable Mg-x (1, 3 and 5wt.\%) Sn-1Zn-0.5Ca alloys. Materials, 2018, 11, 2378.

[68] Jin Y M, Blawert C, Yang H, Wiese B, Feyerabend F, Bohlen J, Mei D, Deng M, Silva C M, Scharnagl N, Strecker K, Bode J, Vogt C, Willumeit-Römer R. Microstructure-corrosion behaviour relationship of micro-alloyed Mg-0.5Zn alloy with the addition of $\mathrm{Ca}, \mathrm{Sr}, \mathrm{Ag}$, In and $\mathrm{Cu}$. Materials \& Design, 2020, 195, 108980.

[69] Hernández-Cortés A A, Escobedo-Bocardo J C, Cortés-Hernández D A, Almanza-Robles J M. Effect of gallium content and heat treatment on the microstructure and corrosion rate of magnesium binary alloys. Metals, 2019, 9, 990.

[70] Kodetova' V, Smola B, Stulı'kova' I, Kudrnova' H, Vlach M, Neubert V. Mechanical and thermal properties and corrosion behaviour of heat-treated Mg-Y-Nd-Ag alloys. Journal of Thermal Analysis and Calorimetry, 2019, 3, 2167-2174.

[71] Liu J N, Bian D, Zheng Y F, Chu X, Lin Y L, Wang M, Lin Z F, Li M, Zhang Y, Guan S K. Comparative in vitro study on binary Mg-RE (Sc, Y, La, Ce, Pr, Nd, Sm, Eu, Gd, Tb, Dy, $\mathrm{Ho}, \mathrm{Er}, \mathrm{Tm}, \mathrm{Yb}$ and $\mathrm{Lu}$ ) alloy systems. Acta Biomaterialia, 2019, 102, 508-528.

[72] Bahmani A, Arthanari S, Shin K S. Improvement of corrosion resistance and mechanical properties of a magnesium alloy using screw rolling. Journal of Alloys and Compounds, 2020, 813, 152155 .
[73] Turen Y U, Zengin H, Sun Y, Ahlatci H, Unal M. Effects of 1wt.\% Ti, In, and Sn additions on the microstructure, mechanical and corrosion properties of the as-cast and hot-rolled AM60 magnesium alloys. Metal Science and Heat, 2019, 61, 318-324.

[74] Jiang P L, Blawert C, Hou R Q, Bohlen J, Konchakova N, Zheludkevich M L.A comprehensive comparison of the corrosion performance, fatigue behavior and mechanical properties of micro-alloyed $\mathrm{MgZnCa}$ and $\mathrm{MgZnGe}$ alloys. Materials \& Design, 2019, 185, 108285.

[75] Feng Y J, Wei L, Chen X B, Li M C, Cheng Y F, Li Q. Unexpected cathodic role of $\mathrm{Mg} 41 \mathrm{Sm} 5$ phase in mitigating localized corrosion of extruded $\mathrm{Mg}-\mathrm{Sm}-\mathrm{Zn}-\mathrm{Zr}$ alloy in $\mathrm{NaCl}$ solution. Corrosion Science, 2019, 159, 108133.

[76] Miao H, Huang H, Shi Y, Zhang H, Pei J, Yuan G. Effects of solution treatment before extrusion on the microstructure, mechanical properties and corrosion of Mg-Zn-Gd alloy in vitro. Corrosion Science, 2017, 122, 90-99.

[77] Sekar P, Sanna N, Desai V. Enhancement of resistance to galvanic corrosion of ZE41 Mg alloy by equal channel angular pressing. Materials and Corrosion, 2019, 71, 571-584.

[78] Koleini S, Idris M H, Jafari H. Influence of hot rolling parameters on microstructure and biodegradability of $\mathrm{Mg}-1 \mathrm{Ca}$ alloy in simulated body fluid. Materials \& Design, 2012, 33, 20-25.

[79] Yu Z L, Chen J H, Yan H G, Xia W J, Su B, Gong X L, Guo H. Degradation, stress corrosion cracking behavior and cytocompatibility of high strain rate rolled $\mathrm{Mg}-\mathrm{Zn}-\mathrm{Sr}$ alloys. Materials Letters, 2020, 260, 126920.

[80] Kim H S, Kim W J. Enhanced corrosion resistance of ultrafine-grained AZ61 alloy containing very fine particles of Mg17Al12 phase. Corrosion Science, 2013, 75, 228-238.

[81] Nene S S, Kashyap B P, Prabhu N, Estrin Y, Al-Samman T. Microstructure refinement and its effect on specific strength and bio-corrosion resistance in ultralight Mg-4Li-1Ca (LC41) alloy by hot rolling. Journal of Alloys and Compounds, 2014, 615, 501-506.

[82] Xiang Q, Jiang B, Zhang Y X, Chen X B, Song J F, Xu J Y, Fang L, Pan F S. Effect of rolling-induced microstructure on corrosion behaviour of an as-extruded $\mathrm{Mg}-5 \mathrm{Li}-1 \mathrm{Al}$ alloy sheet. Corrosion Science, 2017, 119, 14-22.

[83] Pawar S, Slater T J A, Burnett T L, Zhou X, Scamans G M, Fan Z, Thompson G E, Withers P J. Crystallographic effects on the corrosion of twin roll cast AZ31 Mg alloy sheet. Acta Materialia, 2017, 133, 90-99.

[84] Wang N, Mu Y, Xiong W, Zhang J, Li Q, Shi Z. Effect of crystallographic orientation on the discharge and corrosion 
behaviour of AP65 magnesium alloy anodes. Corrosion Science, 2018, 144, 107-126.

[85] Xin R L, Li B, Li L, Liu Q. Influence of texture on corrosion rate of AZ31 Mg alloy in 3.5wt.\% NaCl. Materials \& Design, 2011, 32, 4548-4552.

[86] Jia H M, Feng X H, Yang Y S. Effect of crystal orientation on corrosion behavior of directionally solidified Mg-4wt $\%$ Zn alloy. Journal of Materials Science \& Technology, 2018, 34, 1229-1235.

[87] Zhang X C, Zhong F, Li X P, Liu B, Zhang C Y, Buhe B, Zhang T, Wang F H. The effect of hot extrusion on the microstructure and anti-corrosion performance of LDHs conversion coating on AZ91D magnesium alloy. Journal of Alloys and Compounds, 2019, 788, 756-767.

[88] Zou G D, Peng Q M, Wang Y N, Liu B Z. The effect of extension twinning on the electrochemical corrosion properties of Mg-Y alloys. Journal of Alloys and Compounds, 2015, 618, 44-48.

[89] Yang Q S, Jiang B, Xiang Q, Luo S Q, Yu X W, Pan F S. Microstructure evolution and corrosion performance of AZ31 magnesium alloy sheets. Rare Metal Materials and Engineering, 2016, 45, 1674-1677.

[90] Pulido-González N, Torres B, García-Rodríguez S, Rodrigo P, Rams J. Mg-1Zn-1Ca alloy for biomedical applications. Influence of the secondary phases on the mechanical and corrosion behaviour. Journal of Alloys and Compounds, 2020, 831, 154735.

[91] Gu X J, Cheng W L, Cheng S M, Yu H, Wang Z F, Wang H X, Wang L F. Discharge behavior of Mg-Sn-Zn-Ag alloys with different Sn contents as anodes for Mg-air batteries. Journal of the Electrochemical Society, 2020, 167, 020501.

[92] Gong X L, Chen J H, Yan H G, Xia W J, Su B, Chen M X, Yin $\mathrm{H}$. In vitro degradation and cytocompatibility of as-cast Mg-5Zn-xSr alloys. Journal of Materials Engineering and Performance, 2020, 29, 434-446.

[93] Niu H Y, Deng K K, Nie K B, Wang C J, Liang W, Wu Y C. Degradation behavior of Mg-4Zn-2Ni alloy with high strength and high degradation rate. Materials Chemistry and Physics, 2020, 249, 123131.

[94] Elkaiam L, Hakimi O, Aghion E. Stress corrosion and corrosion fatigue of biodegradable $\mathrm{Mg}-\mathrm{Zn}-\mathrm{Nd}-\mathrm{Y}-\mathrm{Zr}$ alloy in in-vitro conditions. Metals, 2020, 10, 791.

[95] Buzolin R H, Volovitch P, Maltseva A, Lamaka S, Blawert C, Mendis C L, Andreas L, Karl U K, Hort N. Thixomolded AZ91D and MRI153M magnesium alloys and their enhanced corrosion resistance. Materials and Corrosion, 2020, 71, 339-351.
[96] Bahmani A, Arthanari S, Shin K S. Corrosion behavior of Mg-Mn-Ca alloy: Influences of Al, Sn and Zn. Journal of Magnesium \& Alloys, 2019, 7, 38-46.

[97] Wang R, Li Q, Wang N, Peng C, Feng Y. Effect of lithium on the discharge and corrosion behavior of $\mathrm{Mg}-3 \mathrm{wt} . \% \mathrm{Al}$ alloy as the anode for seawater activated battery. Journal of Materials Engineering and Performance, 2018, 27, 6552-6563.

[98] Fernandes M T, da Silva L M, de Freitas B X, Domingues G, de Castro J A, dos Santos C. Effects of Zn content on surface deformability and corrosion resistance of $\mathrm{MgZnMnCa}$ alloys. International Journal of Materials Research, 2020, 111, 511-518.

[99] Woo S K, Blawert C, Yasakau K A, Yi S B, Scharnagl N, Suh B C, Kim Y M, You B S, Yim C D. Effects of combined addition of $\mathrm{Ca}$ and $\mathrm{Y}$ on the corrosion behaviours of die-cast AZ91D magnesium alloy. Corrosion Science, 2020, 166, 108451.

[100]Minárik P, Zemková M, Lukáč F, Bohlen J, Knapek M, Král R. Microstructure of the novel biomedical Mg-4Y-3Nd alloy prepared by spark plasma sintering. Journal of Alloys and Compounds, 2020, 819, 153008.

[101]Jana A, Das M, Balla V K. Effect of heat treatment on microstructure, mechanical, corrosion and biocompatibility of Mg-Zn-Zr-Gd-Nd alloy. Journal of Alloys and Compounds, 2020, 821, 153462.

[102]Chen X R, Zou Q, Le Q C, Hou J, Guo R Z, Wang H N, Hu C L, Bao L, Wang T, Zhao D Z, Yu F X, Atrens A. The quasicrystal of Mg-Zn-Y on discharge and electrochemical behaviors as the anode for Mg-air battery. Journal of Power Sources, 2020, 451, 227807.

[103]Parfenov E V, Kulyasova O B, Mukaeva V R, Mingo B, Farrakhov R G, Cherneikina Y V, Yerokhin A, Zheng Y F, Valiev R Z. Influence of ultra-fine grain structure on corrosion behaviour of biodegradable $\mathrm{Mg}-1 \mathrm{Ca}$ alloy. Corrosion Science, 2020, 163, 108303.

[104]Luo Y F, Deng Y L, Guan L Q, Ye L Y, Guo X B. The microstructure and corrosion resistance of as-extruded Mg-6Gd-2Y-(0-1.5) Nd-0.2Zr alloys. Materials \& Design, 2019, 186, 108289.

[105]Song D, Li C, Liang N N, Yang F L, Jiang J H, Sun J P, Wu G S, Ma A B, Ma X L. Simultaneously improving corrosion resistance and mechanical properties of a magnesium alloy via equal-channel angular pressing and post water annealing. Materials \& Design, 2019, 166, 107621.

[106]Ghali E, Dietzel W, Kainer K U. General and localized corrosion of magnesium alloys: A critical review. Journal of Materials Engineering and Performance, 2013, 22, 
2875-2891.

[107]Skar J I. Corrosion and corrosion prevention of magnesium alloys. Materials and Corrosion, 1999, 50, 2-6.

[108]Song G L, Atrens A. Corrosion mechanisms of magnesium alloys. Advanced Engineering Materials, 1999, 1, 11-33.

[109]Kappes M, Iannuzzi M, Carranza R M. Pre-exposure embrittlement and stress corrosion cracking of magnesium alloy AZ31B in chloride solutions. Corrosion, 2014, 70, 667-677.

[110]Song R G, Blawert C, Dietzel W, Atrens A. A study on stress corrosion cracking and hydrogen embrittlement of AZ31 magnesium alloy. Materials Science and Engineering: A, 2005, 399, 308-317.

[111]Atrens A, Winzer N, Song G L, Dietzel W. Stress corrosion cracking and hydrogen diffusion in magnesium. Advanced Engineering Materials, 2006, 8, 749-751.

[112]Zeng R C, Zhang J, Huang W J, Dietzel W, Kainer K U, Blawert C, Wei K. Review of studies on corrosion of magnesium alloys. Transactions of Nonferrous Metals Society of China, 2006, 16, s763-s771.

[113]Neinhuis W B. Purity of the sacred lotus, or escape from contamination in biological surfaces. Planta, 1997, 202, 1-8.

[114]Neinhuis C, Barthlott W. Characterization and distribution of water-repellent, self-cleaning plant surfaces. Annals of Botany, 1997, 79, 667-677.

[115]Feng L, Li S H, Li Y S, Li H J, Zhang L J, Zhai J, Song L Y, Liu B Q, Jiang L, Zhu D B. Super-hydrophobic surfaces: From natural to artificial. Advanced Materials. 2002, 14, $1857-1860$.

[116]Yan Y Y, Gao N, Barthlott W. Mimicking natural superhydrophobic surfaces and grasping the wetting process: A review on recent progress in preparing superhydrophobic surfaces. Advances in Colloid and Interface Science, 2011, 169, 80-105.

[117]Ensikat H J, Ditsche-Kuru P, Neinhuis C, Barthlott W. Superhydrophobicity in perfection: The outstanding properties of the lotus leaf. Beilstein Journal of Nanotechnology, 2011, 2,152-161.

[118]Ferrari M, Benedetti A. Superhydrophobic surfaces for applications in seawater. Advances in Colloid and Interface Science, 2015, 222, 291-304.

[119]Li C L, Sun Y C, Cheng M, Sun S Q, Hu S Q. Fabrication and characterization of $\mathrm{TiO}_{2} /$ polysiloxane resin composite coating with full-thickness super-hydrophobicity. Chemical Engineering Journal, 2018, 333, 361-369.

[120]Liu B Y, Xue C H, An Q F, Jia S T, Xu M M. Fabrication of superhydrophobic coatings with edible materials for super-repelling non-newtonian liquid foods. Chemical Engineering Journal, 2019, 371, 833-841.

[121]Khorsand S, Raeissi K, Ashrafizadeh F, Arenas M A, Conde A. Corrosion behaviour of super-hydrophobic electrodeposited nickel-cobalt alloy film. Applied Surface Science, 2016, 364, 349-357.

[122]Liu Y, Gao H P, Li S Y, Han Z W, Ren L Q. Bioinspired platform with reversibly switchable wettability for transfer and storage of droplets. Chemical Engineering Journal, 2018, 337, 697-708.

[123]Gao X Y, Guo Z G. Biomimetic superhydrophobic surfaces with transition metals and their oxides: A review. Journal of Bionic Engineering, 2017, 14, 401-439.

[124]Li J A, Liu X H, Ye Y P, Zhou H D, Chen J M. Fabrication of superhydrophobic $\mathrm{CuO}$ surfaces with tunable water adhesion. Journal of Physical Chemistry C, 2011, 115, 4726-4729.

[125]Feng L, Zhang Y, Xi J, Zhu Y, Wang N, Xia F, Jiang L. Petal effect a superhydrophobic state with high adhesive force. Langmuir: The ACS Journal of Surfaces and Colloids, 2008, 248, 4114-4119.

[126]Zhang M Q, Feng S L, Wang L, Zheng Y M. Lotus effect in wetting and self-cleaning. Biotribology, 2016, 5, 31-43.

[127]Cassie A B D, Baxter S. Wettability of porous surfaces. Transactions of the Faraday Society, 1944, 40, 546.

[128]Liu Y, Yao W G, Wang G Y, Wang Y M, Moita A S, Han Z W, Ren L Q. Reversibly switchable wettability on aluminum alloy substrate corresponding to different $\mathrm{pH}$ droplet and its corrosion resistance. Chemical Engineering Journal, 2016, 303, 565-574.

[129]Zhang J Y, Kang Z X. Effect of different liquid-solid contact models on the corrosion resistance of superhydrophobic magnesium surfaces. Corrosion Science, 2014, 87, 452-459.

[130]Li D W, Wang H Y, Luo D, Liu Y, Han Z W, Ren L Q. Corrosion resistance controllable of biomimetic superhydrophobic microstructured magnesium alloy by controlled adhesion. Surface and Coatings Technology, 2018, 347, 173-180.

[131]Bohn H F, Federle W. Insect aquaplaning: Nepenthes pitcher plants capture prey with the peristome, a fully wettable water-lubricated anisotropic surface. Proceedings of The $\mathrm{Na}$ tional Academy of Sciences of The United States of America, 2004, 101, 14138-14143.

[132]Wong T S, Kang S H, Sindy K Y, Elizabeth J S, Hatton B D. Grinthal A, Aizenberg J. Bioinspired self-repairing slippery surfaces with pressure-stable omniphobicity. Nature, 2011, 
477, 443-447.

[133]Preston D J, Song Y, Lu Z, Antao D S, Wang E N. Design of lubricant infused surfaces. ACS Applied Materials \& Interfaces, 2017, 9, 42383-42392.

[134]Anand S, Paxson A T, Dhiman R, Smith J D, Varanasi K $\mathrm{K}$. Enhanced condensation on lubricant-impregnated nanotextured surfaces. ACS Nano, 2012, 6, 10122-10129.

[135]Barthwal S, Lim S H. Robust and chemically stable superhydrophobic aluminum-alloy surface with enhanced corrosion-resistance properties. International Journal of Precision Engineering and Manufacturing-Green Technology, 2020, 7, 481-492.

[136]Liu E Y, Yin X L, Hu J H, Yu S R, Zhao Y, Xiong W. Fabrication of a biomimetic hierarchical superhydrophobic $\mathrm{Cu}-\mathrm{Ni}$ coating with self-cleaning and anti-corrosion properties. Colloids and Surfaces A: Physicochemical and Engineering Aspects, 2020, 586, 124223.

[137]Miao Y Y, Zhang D L, Cao N, Yang L Y, Ju H, Boukherroub R, Lin X Q, Li H P, Jin Y H. Mussel-inspired superhydrophobic surfaces on $316 \mathrm{~L}$ stainless steel with enhanced corrosion resistance. Metallurgical and Materials Transactions A: Physical Metallurgy and Materials Science: Guest Editorial, 2019, 51, 909-919.

[138]Zhang F, Zhang C L, Song L, Zeng R C, Li S Q, Cui H Z. Fabrication of the superhydrophobic surface on magnesium alloy and its corrosion resistance. Journal of Materials Science, 2015, 31, 1139-1143.

[139]Gao R, Liu Q, Wang J, Zhang X F, Yang W L, Liu J Y, Liu L H. Fabrication of fibrous szaibelyite with hierarchical structure superhydrophobic coating on AZ31 magnesium alloy for corrosion protection. Chemical Engineering Journal, 2014, 241, 352-359.

[140]Wei D S, Wang J G, Wang H Y, Liu Y, Li S Y, Li D W. Anti-corrosion behaviour of superwetting structured surfaces on Mg-9Al-1Zn magnesium alloy. Applied Surface Science, 2019, 483, 1017-1026.

[141]Gnedenkov S V, Sinebryukhov S L, Egorkin V S, Mashtalyar D V, Emelyanenko A M, Boinovich L B. Electrochemical properties of the superhydrophobic coatings on metals and alloys. Journal of the Taiwan Institute of Chemical Engineers, 2014, 45, 3075-3080.

[142]Li Z J, Yuan Y. Preparation and characterization of superhydrophobic composite coatings on a magnesium-lithium alloy. RSC Advances, 2016, 6, 90587-90596.

[143]Boinovich L B, Emelyanenko A M, Pashinin A S, Gnedenkov S V, Egorkin V S, Sinebryukhov S L. Mg alloy treatment for superhydrophobic anticorrosion coating formation.
Surface Innovations, 2013, 1, 162-172.

[144]Liu Q, Chen D X, Kang Z X. One-step electrodeposition process to fabricate corrosion-resistant superhydrophobic surface on magnesium alloy, ACS Applied Materials \& Interfaces, 2015, 7, 1859-1867.

[145]Liu Y, Yin X M, Zhang J J, Yu S R, Han Z W, Ren L Q. A electro-deposition process for fabrication of biomimetic super-hydrophobic surface and its corrosion resistance on magnesium alloy. Electrochimica Acta, 2014, 125, 395-403.

[146]Huang J J. Electrodeposition of superhydrophobic hydroxyapatite/magnesium phosphate on a magnesium alloy substrate for enhanced corrosion resistance. International Journal of Electrochemical Science, 2017, 12, 4654-4663.

[147]Chu Q W, Liang J, Hao J C. Facile fabrication of a robust super-hydrophobic surface on magnesium alloy. Colloids and Surfaces A: Physicochemical and Engineering Aspects, 2014, 443, 118-122.

[148]Zhang Y F, Tang S W, Hu J, Lin T G. Formation mechanism and corrosion resistance of the hydrophobic coating on anodized magnesium. Corrosion Science, 2016, 111, 334-343.

[149]Liu Y, Yao W G, Yin X M, Wang H Y, Han Z W, Ren L Q. Controlling wettability for improved corrosion inhibition on magnesium alloy as biomedical implant materials. Advanced Materials Interfaces, 2016, 3, 1500723.

[150]Zhang S J, Cao D L, Xu L K, Lin Z F, Meng R Q. Fabrication of a superhydrophobic polypropylene coating on magnesium alloy with improved corrosion resistance. International Journal of Electrochemical Science, 2020, 15, 177-187.

[151]Yang N, Li J C, Bai N N, Xu L, Li Q. One step phase separation process to fabricate superhydrophobic PVC films and its corrosion prevention for AZ91D magnesium alloy. $M a$ terials Science and Engineering B-Advanced Functional Solid-State Materials, 2016, 209, 1-9.

[152]Wu C Q, Liu Q, Chen R R, Liu J Y, Zhang H S, Li R M, Takahashi K, Liu P L, Wang J. Fabrication of ZIF-8@SiO micro/nano hierarchical superhydrophobic surface on AZ31 magnesium alloy with impressive corrosion resistance and abrasion resistance. ACS Applied Materials \& Interfaces, 2017, 9, 11106-11115.

[153]Ou J F, Chen X. Corrosion resistance of phytic acid/Ce (III) nanocomposite coating with superhydrophobicity on magnesium. Journal of Alloys and Compounds, 2019, 787, 145-151.

[154]Ishizaki T, Sakamoto M. Facile formation of biomimetic color-tuned superhydrophobic magnesium alloy with corrosion resistance. Langmuir The ACS Journal of Surfaces \& Colloids, 2011, 27, 2375-2381. 
[155]Wang L, Yang J Y, Zhu Y, Li Z H, Shen T, Yang D Q. An environment-friendly fabrication of superhydrophobic surfaces on steel and magnesium alloy. Materials Letters, 2016, 171, 297-299.

[156]Liu K, Zhang M, Zhai J, Wang J, Jiang L. Bioinspired construction of Mg-Li alloys surfaces with stable superhydrophobicity and improved corrosion resistance. Applied Physics Letters, 2008, 92, 183103.

[157]Yao Q S, Li Z C, Qiu Z M, Zhang F, Chen X B, Chen D C, Guan S K, Zeng R C. Corrosion resistance of $\mathrm{Mg}(\mathrm{OH})(2) / \mathrm{Mg}$-Al-layered double hydroxide coatings on magnesium alloy AZ31: Influence of hydrolysis degree of silane. Rare Metals, 2019, 38, 629-641.

[158]Yeganeh M, Omidi M, Eskandari M. Superhydrophobic surface of AZ31 alloy fabricated by chemical treatment in the $\mathrm{NiSO}_{4}$ solution. Journal of Materials Engineering and Performance, 2018, 27, 3951-3960.

[159]Jia J, Fan J F, Xu B S, Dong H B. Microstructure and properties of the super-hydrophobic films fabricated on magnesium alloys. Journal of Alloys and Compounds, 2013, 554, 142-146.

[160]Wang Z H, Zhang J M, Li Y, Bai L J, Zhang G J. Enhanced corrosion resistance of micro-arc oxidation coated magnesium alloy by superhydrophobic Mg-Al layered double hydroxide coating. Transactions of Nonferrous Metals Society of China, 2019, 29, 2066-2077.

[161]Cui X J, Lin X Z, Liu C H, Yang R S, Zheng X W, Gong M. Fabrication and corrosion resistance of a hydrophobic micro-arc oxidation coating on AZ31 Mg alloy. Corrosion Science, 2014, 90, 402-412.

[162]Jin Q, Tian G Y, Li J X, Zhao Y, Yan H. The study on corrosion resistance of superhydrophobic magnesium hydroxide coating on AZ31B magnesium alloy. Colloids and Surfaces A: Physicochemical and Engineering Aspects, 2019, 577, 8-16.

[163]Wan H R, Hu X F. One-step solve-thermal process for the construction of anticorrosion bionic superhydrophobic surfaces on magnesium alloy. Materials Letters, 2016, 174, 209-212.

[164]Zang D M, Zhu R W, Wu C X, Yu X Q, Zhang Y F. Fabrication of stable superhydrophobic surface with improved anticorrosion property on magnesium alloy. Scripta Materialia, 2013, 69, 614-617.

[165]Liu X, He H Q, Zhang T C, Ouyang L, Zhang Y X, Yuan S J. Superhydrophobic and self-healing dual-function coatings based on mercaptabenzimidazole inhibitor-loaded magnesium silicate nanotubes for corrosion protection of AZ31B magnesium alloys. Chemical Engineering Journal, 2021, 404, 127106.

[166]Zhang Z Q, Zeng R C, Lin C G, Wang L, Chen X B, Chen D C. Corrosion resistance of self-cleaning silane/polypropylene composite coatings on magnesium alloy AZ31. Journal of Materials Science \& Technology, 2020, 41, 43-55.

[167]Ishizaki T, Masuda Y, Sakamoto M. Corrosion resistance and durability of superhydrophobic surface formed on magnesium alloy coated with nanostructured cerium oxide film and fluoroalkylsilane molecules in corrosive $\mathrm{NaCl}$ aqueous solution. Langmuir, 2011, 27, 4780-4788.

[168]Wu C Q, Liu Q, Liu J Y, Chen R R, Takahashi K, Liu L H, Li R M, Liu P L, Wang J. Hierarchical flower like double-layer superhydrophobic films fabricated on AZ31 for corrosion protection and self-cleaning. New Journal or Chemistry, 2017, 41, 12767-12776.

[169]Liu L, Lei J L, Li L J, Zhang J, Shang B, He J X, Li N B, Pan F S. Robust rare-earth-containing superhydrophobic coatings for strong protection of magnesium and aluminum alloys. Advanced Materials Interfaces, 2018, 5, 1800213.

[170]Qian Z Q, Wang S D, Ye X S, Liu Z, Wu Z J. Corrosion resistance and wetting properties of silica-based superhydrophobic coatings on AZ31B Mg alloy surfaces. Applied Surface Science, 2018, 453, 1-10.

[171]Luo Y, Yao W, Fu W, Wu L, Zhang D, Pan F. Preparing superhydrophobic nanocomposite coating with $\mathrm{SiO}_{2}$ nanoparticles on magnesium alloy. Surface Engineering, 2020, $1-8$.

[172] Wang S D, Ye X S, Zhang H F, Qian Z Q, Li Q, Wu Z J, Li S T. Superhydrophobic silane/fluorinated attapulgite@ $\mathrm{SiO}(2)$ composite coatings on magnesium alloy for corrosion protection. Chemistryselect, 2020, 5, 10329-10338.

[173]Wang S H, Guo X W, Xie Y J, Liu L H, Yang H Y, Zhu R Y, Gong J, Peng L M, Ding W J. Preparation of superhydrophobic silica film on Mg-Nd-Zn-Zr magnesium alloy with enhanced corrosion resistance by combining micro-arc oxidation and sol-gel method. Surface \& Coatings Technology, 2012, 213, 192-201.

[174]Zhang Z Q, Zeng R C, Yan W, Lin C G, Wang L, Wang Z L, Chen D C. Corrosion resistance of one-step superhydrophobic polypropylene coating on magnesium hydroxide-pretreated magnesium alloy AZ31. Journal of Alloys and Compounds, 2020, 821, 153515.

[175]Jiang D, Zhou H, Wan S, Cai G Y, Dong Z H. Fabrication of superhydrophobic coating on magnesium alloy with improved corrosion resistance by combining micro-arc oxida- 
tion and cyclic assembly. Surface \& Coatings Technology, 2018, 339, 155-166.

[176]Zhou H M, Chen R R, Liu Q, Liu J Y, Yu J, Wang C, Zhang M, Liu P L, Wang J. Fabrication of $\mathrm{ZnO} /$ epoxy resin superhydrophobic coating on AZ31 magnesium alloy. Chemical Engineering Journal, 2019, 368, 261-272.

[177]Siddiqui A R, Maurya R, Katiyar P K, Balani K. Superhydrophobic, self-cleaning carbon nanofiber CVD coating for corrosion protection of AISI 1020 steel and AZ31 magnesium alloys. Surface and Coatings Technology, 2020, 404, 126421.

[178]Yuan J, Li P, Yuan R, Mao D L. Fabrication and corrosion resistance of a superhydrophobic Ni-P/Ni-3(NO3)(2)(OH)(4) multilayer protective coating on magnesium alloy. ACS Omega, 2020, 5, 24247-24255.

[179]Xu W J, Song J L, Sun J, Lu Y, Yu Z Y. Rapid fabrication of large-area, corrosion-resistant superhydrophobic $\mathrm{Mg}$ alloy surfaces. ACS Applied Materials \& Interfaces, 2011, 3, 4404-4414.

[180]She Z X, Li Q, Wang Z W, Tan C, Zhou J C, Li L Q. Highly anticorrosion, self-cleaning superhydrophobic Ni-Co surface fabricated on AZ91D magnesium alloy. Surface \& Coatings Technology, 2014, 251, 7-14.

[181]Liu Y, Xue J Z, Luo D, Wang H Y, Gong X, Han Z W, Ren L Q. One-step fabrication of biomimetic superhydrophobic surface by electrodeposition on magnesium alloy and its corrosion inhibition. Journal of Colloid and Interface Science, 2017, 491, 313-320.

[182]Kuang J, Ba Z X, Li Z Z, Wang Z Z, Qiu J H. The study on corrosion resistance of superhydrophobic coatings on magnesium. Applied Surface Science, 2020, 501, 153515.

[183]Zhong Y X, Hu J, Zhang Y F, Tang S W. The one-step electroposition of superhydrophobic surface on AZ31 magnesium alloy and its time-dependence corrosion resistance in $\mathrm{NaCl}$ solution. Applied Surface Science, 2018, 427, 1193-1201.

[184]Yin Z Z, Zhang Z Q, Tian X J, Wang Z L, Zeng R C. Corrosion resistance and durability of superhydrophobic coating on AZ31 Mg alloy via one-step electrodeposition. Acta Metallurgica Sinica-English Letters, 2021, 34, 25-38.

[185]Han M, Go S, Ahn Y. Fabrication of superhydrophobic surface on magnesium substrate by chemical etching. Bulletin of The Korean Chemical Society, 2012, 33, 1363-1366.

[186]Wan P, Wu J Y, Tan L L, Zhang B C, Yang K. Research on super-hydrophobic surface of biodegradable magnesium alloys used for vascular stents. Materials Science \& Engineering C-Materials for Biological Applications, 2013, 33,
2885-2890.

[187]Zhang J L, Gu C D, Tong Y Y, Yan W, Tu J P. A smart superhydrophobic coating on AZ31B magnesium alloy with self-healing effect. Advanced Materials Interfaces, 2016, 3, UNSP 1500694.

[188]Zhang L S, Jiang Y, Zai W, Li G Y, Liu S C, Lian J S, Jiang Z H. Fabrication of superhydrophobic calcium phosphate coating on $\mathrm{Mg}-\mathrm{Zn}-\mathrm{Ca}$ alloy and its corrosion resistance. Journal of Materials Engineering and Performance, 2017, 26, 6117-6129.

[189]Zhao M, Wang X L, Song H, Li J G, He G P, Gui Y H, Feng W. Fabrication of a superhydrophobic phosphate/fatty-acid salt compound coating on magnesium alloy. ECS Electrochemistry Letters, 2015, 4, C19-C21.

[190]Xu J K, Xia K, Lian Z X, Zhang L S, Yu H D, Yu Z J, Weng Z K, Wang Z B. Surface properties on magnesium alloy and corrosion behaviour based high-speed wire electrical discharge machine power tubes. Micro \& Nano Letters, 2015, 11, 15-19.

[191]Qiu R X, Li C, Tong W, Xiong D S, Li Z X, Wu Z L. High-speed wire electrical discharge machining to create superhydrophobic surfaces for magnesium alloys with high corrosion and wear resistance. Materials and Corrosion-Werkstoffe und Korrosion, 2020, 71, 1711-1720.

[192]Gao R, Wang J, Zhang X F, Yan H J, Yang W L, Liu Q, Zhang M L, Liu L H, Takahashi K. Fabrication of superhydrophobic magnesium alloy through the oxidation of hydrogen peroxide. Colloids and Surfaces A-Physicochemical and Engineering Aspects, 2013, 436, 906-911.

[193]Li J H, Liu Q, Wang Y L, Chen R R, Takahashi K, Li R M, Liu L H, Wang J. Formation of a corrosion-resistant and anti-icing superhydrophobic surface on magnesium alloy via a single-step method. Journal of The Electrochemical Society, 2016, 163, C213-C220.

[194]Zhang F, Zhang C L, Zeng R C, Song L, Guo L, Huang X W. Corrosion resistance of the superhydrophobic $\mathrm{Mg}(\mathrm{OH})(2) / \mathrm{Mg}-\mathrm{Al}$ layered double hydroxide coatings on magnesium alloys. Metals, 2016, 6, 85.

[195]Hu W Q, Yuan X G. Facile hydrothermal synthesis of $\mathrm{SnO}_{2}$ nanospheres as photocatalysts. Journal of Nanomaterials, 2017, 2017, 1-6.

[196]Hu W Q, Yuan X G, Liu X L, Guan Y, Wu X. Hierarchical $\mathrm{SnO}_{2}$ nanostructures as high efficient photocatalysts for the degradation of organic dyes. Journal of Sol-Gel Science and Technology, 2017, 84, 316-322.

[197]Liu Q, Kang Z X. One-step electrodeposition process to fabricate superhydrophobic surface with improved anticor- 
rosion property on magnesium alloy. Materials Letters, 2014, 137, 210-213.

[198]She Z X, Li Q, Wang Z W, Li L Q, Chen F N, Zhou J C. Novel method for controllable fabrication of a superhydrophobic $\mathrm{CuO}$ surface on AZ91D magnesium alloy. ACS Applied Materials \& Interfaces, 2012, 4, 4348-4356.

[199]Yeganeh M, Mohammadi N. Superhydrophobic surface of $\mathrm{Mg}$ alloys: A review. Journal of Magnesium and Alloys, 2018, 6, 59-70.

[200]Cui L Y, Liu H P, Zhang W L, Han Z Z, Deng M X, Zeng R C, Li S Q, Wang Z L. Corrosion resistance of a superhydrophobic micro-arc oxidation coating on $\mathrm{Mg}-4 \mathrm{Li}-1 \mathrm{Ca}$ alloy. Journal of Magnesium and Alloys, 2017, 33, 1263-1271.

[201]Li W, Kang Z X. Fabrication of corrosion resistant superhydrophobic surface with self-cleaning property on magnesium alloy and its mechanical stability. Surface \& Coatings Technology, 2014, 253, 205-213.

[202]Song J L, Pan W H, Wang K, Chen F Z, Sun Y W. Fabrication of micro-reentrant structures by liquid/gas interface shape-regulated electrochemical deposition. International Journal of Machine Tools and Manufacture, 2020, 159, 103637.

[203]Rius-Ayra O, LLorca-Isern N. Growth of a superhydrophobic coating on an aluminium substrate with strong adhesive properties and showing efficient oil/water separation. Thin Solid Films, 2020, 710, 138259.

[204]Gnedenkov S V, Egorkin V S, Sinebryukhov S L, Vyaliy I E, Pashinin A S, Emelyanenko A M, Boinovich L B. Formation and electrochemical properties of the superhydrophobic nanocomposite coating on PEO pretreated $\mathrm{Mg}-\mathrm{Mn}-\mathrm{Ce}$ magnesium alloy. Surface \& Coatings Technology, 2013, 232, 240-246.

[205]Zhang Y F, Feyerabend F, Tang S W, Hu J, Lu X P, Blawert C, Lin T G. A study of degradation resistance and cytocompatibility of super-hydrophobic coating on magnesium. Materials Science \& Engineering C-Materials for Biological Applications, 2017, 78, 405-412.

[206]Zhang C L, Zhang F, Song L, Zeng R C, Li S Q, Han E H. Corrosion resistance of a superhydrophobic surface on micro-arc oxidation coated Mg-Li-Ca alloy. Journal of Alloys and Compounds, 2017, 728, 815-826.

[207]Liu A H, Xu J L. Preparation and corrosion resistance of superhydrophobic coatings on AZ31 magnesium alloy. Transactions of Nonferrous Metals Society of China, 2018, 28, 2287-2293.

[208]Li D W, Wang H Y, Liu Y, Wei D S, Zhao Z X. Large-scale fabrication of durable and robust super-hydrophobic spray coatings with excellent repairable and anti-corrosion performance. Chemical Engineering Journal, 2019, 367, 169-179.

[209]Shi L T, Hu J, Lin X D, Fang L, Wu F, Xie J, Meng F M. A robust superhydrophobic PPS-PTFE/ $\mathrm{SiO}_{2}$ composite coating on $\mathrm{AZ} 31 \mathrm{Mg}$ alloy with excellent wear and corrosion resistance properties. Journal of Alloys and Compounds, 2017, 721, 157-163.

[210]Li X, Li B, Li Y, Sun J Q. Nonfluorinated, transparent, and spontaneous self-healing superhydrophobic coatings enabled by supramolecular polymers. Chemical Engineering Journal, 2021, 404, 126504.

[211]Sanabria-Mafaile J, San Martin-Martinez E, Cruz-Orea A. Thermal properties of superhydrophobic films applied in ceramic tiles. Colloids and Surfaces A Physicochemical and Engineering Aspects, 2020, 607, 125524.

[212]Zhao L, Liu Q, Gao R, Wang J, Yang W L, Liu L H. One-step method for the fabrication of superhydrophobic surface on magnesium alloy and its corrosion protection, antifouling performance. Corrosion Science, 2014, 80, 177-183.

[213]Xun X W, Wan Y Z, Zhang Q C, Gan D Q, Hu J, Luo H L. Low adhesion superhydrophobic AZ31B magnesium alloy surface with corrosion resistant and anti-bioadhesion properties. Applied Surface Science, 2020, 505, 144566.

[214]Ishizaki T, Shimada Y, Tsunakawa M, Lee H, Yokomizo T, Hisada S, Nakamura K. Rapid fabrication of a crystalline myristic acid-based superhydrophobic film with corrosion resistance on magnesium alloys by the facile one-step immersion process. ACS Omega, 2017, 2, 7904-7915.

[215]Liang M M, Wei Y H, Hou L F, Wang H Y, Li Y G, Guo C L. Fabrication of a super-hydrophobic surface on a magnesium alloy by a simple method. Journal of Alloys and Compounds, 2016, 656, 311-317.

[216]Wang Z W, Li Q, She Z X, Chen F N, Li L Q, Zhang X X, Zhang P. Facile and fast fabrication of superhydrophobic surface on magnesium alloy. Applied Surface Science, 2013, 271, 182-192.

[217]Feng L B, Zhu Y L, Fan W B, Wang Y P, Qiang X H, Liu Y H. Fabrication and corrosion resistance of superhydrophobic magnesium alloy. Applied Physics A-Materials Science \& Processing, 2015, 120, 561-570.

[218]Wang H Y, Wei Y H, Liang M M, Hou L F, Li Y G, Guo C L. Fabrication of stable and corrosion-resisted super-hydrophobic film on $\mathrm{Mg}$ alloy. Colloids and Surfaces A-Physicochemical and Engineering Aspects, 2016, 509, 351-358.

[219]Savio L, Bhavitha K B, Bracco G, Luciano G, Cavallo D, 
Paolini G, Passaglia S, Carraro G, Vattuone L, Masini R, Smerieri M. Correlating hydrophobicity to surface chemistry of microstructured aluminium surfaces. Applied Surface Science, 2021, 542, 148574.

[220]Barthwal S, Lim S H. A durable, fluorine-free, and repairable superhydrophobic aluminum surface with hierarchical micro/nanostructures and its application for continuous oil-water separation. Journal of Membrane Science, 2020, 618, 118716.

[221]Ahuja N, Batra U, Kumar K. Experimental investigation and optimization of wire electrical discharge machining for surface characteristics and corrosion rate of biodegradable $\mathrm{Mg}$ alloy. Journal of Materials Engineering and Performance, 2020, 29, 4117-4129.

[222]Wan Y L, Lou J, Yu Z J, Li X Z, Yu H D. Single-step fabrication of bionic-superhydrophobic surface using reciprocating-type high-speed wire cut electrical discharge machining. Chinese Science Bulletin, 2014, 59, 3691-3695.

[223]Zheng J, Zheng W, Chen A K, Yao J K, Ren Y C, Zhou C, Wu J, Ling W, Bai B, Wang W, Zhang Z W. Sustainability of unconventional machining industry considering impact factors and reduction methods of energy consumption: A review and analysis. Science of The Total Environment, 2020, 722, 137897.

[224]Chen X, Wang Z L, Xu J, Wang Y K, Li J W, Liu H Z. Sustainable production of micro gears combining micro reciprocated wire electrical discharge machining and precision forging. Journal of Cleaner Production, 2018, 188, 1-11.

[225]Li C Y, Gao L, Fan X L, Zeng R C, Chen D C, Zhi K Q. In vitro degradation and cytocompatibility of a low temperature in-situ grown self-healing $\mathrm{Mg}-\mathrm{Al} \mathrm{LDH}$ coating on MAO-coated magnesium alloy AZ31. Bioactive Materials, 2020, 5, 364-376.

[226]Qiu Z, Sun J, Wang R, Zhang Y S, Wu X H. Magnet-induced fabrication of a superhydrophobic surface on ZK60 magnesium alloy. Surface \& Coatings Technology, 2016, 286, 246-250.

[227]Song J L, Xu W J, Lu Y, Liu X, Sun J. Fabrication of superhydrophobic surfaces on $\mathrm{Mg}$ alloy substrates via primary cell corrosion and fluoroalkylsilane modification. Materials and Corrosion-Werkstoffe und Korrosion, 2013, 64, 979-987.

[228]Zang D M, Zhu R W, Zhang W, Yu X Q, Lin L, Guo X L, Liu $\mathrm{M} J$, Jiang L. Corrosion-resistant superhydrophobic coatings on $\mathrm{Mg}$ alloy surfaces inspired by lotus seedpod. Advanced Functional Materials, 2017, 27, 1605446.

[229]Ding C D, Tai Y, Wang D, Tan L H, Fu J J. Superhydropho- bic composite coating with active corrosion resistance for AZ31B magnesium alloy protection. Chemical Engineering Journal, 2019, 357, 518-532.

[230]Nguyen T P N, Brunet P, Coffinier Y, Boukherroub R. Quantitative testing of robustness on super-omniphobic surfaces by drop impact. Langmuir, 2010, 26, 18369-18373.

[231]Gaume L, Gorb S, Rowe N. Function of epidermal surfaces in the trapping efficiency of nepenthes alata pitchers. New Phytologist, 2002, 156, 479-489.

[232]He W Q, Liu P, Zhang J Q, Yao X. Emerging applications of bioinspired slippery surfaces in biomedical fields. Chemistry-A European Journal, 2018, 24, 14864-14877.

[233]Villegas M, Zhang Y X, Abu Jarad N, Soleymani L, Didar T F. Liquid-infused surfaces: A review of theory, design, and applications. ACS Nano, 2019, 13, 8517.

[234]Song T T, Liu Q L, Zhang M L, Chen R R, Takahashi K, Jing X Y, Liu L H, Wang J. Multiple sheet-layered super slippery surfaces based on anodic aluminium oxide and its anticorrosion property. RSC Advances, 2015, 5, 70080-70085.

[235]Inoue T, Koyama A, Kowalski D, Zhu C Y, Aoki Y, Habazaki H. Fluorine-free slippery liquid-infused porous surfaces prepared using hierarchically porous aluminum. Physica Status Solidi A-Applications and Materials Science, 2020, 217, 1900836.

[236]Ouyang Y B, Zhao J, Qiu R, Hu S G, Niu H L, Zhang Y, Chen M. Nanowall enclosed architecture infused by lubricant: A bio-inspired strategy for inhibiting bio-adhesion and bio-corrosion on stainless steel. Surface \& Coatings Technology, 2020, 381, 125143.

[237]Joo J, Kim D, Moon H S, Kim K, Lee J. Durable anti-corrosive oil-impregnated porous surface of magnesium alloy by plasma electrolytic oxidation with hydrothermal treatment. Applied Surface Science, 2020, 509, 145361.

[238]Jiang D, Xia X C, Hou J, Cai G Y, Zhang X X, Dong Z H. A novel coating system with self-reparable slippery surface and active corrosion inhibition for reliable protection of $\mathrm{Mg}$ alloy. Chemical Engineering Journal, 2019, 373, 285-297.

[239]Zhang J L, Gu C D, Tu J P. Robust slippery coating with superior corrosion resistance and anti-icing performance for AZ31B Mg alloy protection. ACS Applied Materials \& Interfaces, 2017, 9, 11247-11257.

[240]Song F, Wu C Q, Chen H L, Liu Q, Liu J Y, Chen R R, Li R $\mathrm{M}$, Wang J. Water-repellent and corrosion-resistance properties of superhydrophobic and lubricant-infused super slippery surfaces. RSC Advances, 2017, 7, 44239-44246.

[241]Li H, Feng X L, Peng Y J, Zeng R C. Durable lubricant-infused coating on magnesium alloy substrate with an- 
ti-biofouling, anti-corrosion properties and excellent thermally assisted healing ability. Nanoscale, 2020, 12, 7700-7711.

[242]Zhang J L, Gu C D, Yan W, Tu J P, Ding X D. Fabrication and corrosion property of conversion films on magnesium alloy from deep eutectic solvent. Surface \& Coatings Technology, 2018, 344, 702-709.

[243]Wang X, Long Y, Mu P, Li J. Silicone oil infused slippery candle soot surface for corrosion inhibition with anti-fouling and self-healing properties. Journal of Adhesion Science and
Technology, 2020, 1, 1-15.

[244]Long Y F, Yin X X, Mu P, Wang Q T, Hu J J, Li J. Slippery liquid-infused porous surface (SLIPS) with superior liquid repellency, anti-corrosion, anti-icing and intensified durability for protecting substrates. Chemical Engineering Journal, 2020, 401, 126137.

[245]Xu J K, Cai Q Q, Yu Z J, Lian Z X, Tian J W, Yu H D. Fabrication and application of metal-based slippery liquid-infused porous surface. Progress in Chemistry, 2021, 33, 958-974. 